\title{
The WISE 2000 and 2001 Field Experiments in Support of the SMOS Mission: Sea Surface L-Band Brightness Temperature Observations and Their Application to Sea Surface Salinity Retrieval
}

Adriano Camps, Senior Member, IEEE, Jordi Font, Mercè Vall-llossera, Member, IEEE, Carolina Gabarró, Ignasi Corbella, Member, IEEE, Núria Duffo, Member, IEEE, Francesc Torres, Sebastián Blanch, Albert Aguasca, Ramón Villarino, Luis Enrique, Jorge José Miranda, Juan José Arenas, Agustí Julià, Jacqueline Etcheto, Vicente Caselles, Alain Weill, Jacqueline Boutin, Stéphanie Contardo, Raquel Niclós, Raúl Rivas, Steven C. Reising, Member, IEEE, P. Wursteisen, Michael Berger, and Manuel Martín-Neira, Member, IEEE

\begin{abstract}
Soil Moisture and Ocean Salinity (SMOS) is an Earth Explorer Opportunity Mission from the European Space Agency with a launch date in 2007. Its goal is to produce global maps of soil moisture and ocean salinity variables for climatic studies using a new dual-polarization L-band (1400-1427 MHz) radiometer Microwave Imaging Radiometer by Aperture Synthesis (MIRAS). SMOS will have multiangular observation capability and can be optionally operated in full-polarimetric mode. At this frequency the sensitivity of the brightness temperature $\left(T_{B}\right)$ to the sea surface salinity (SSS) is low: $0.5 \mathrm{~K} / \mathrm{psu}$ for a sea surface temperature (SST) of $20^{\circ} \mathrm{C}$, decreasing to $0.25 \mathrm{~K} / \mathrm{psu}$ for a SST of $0{ }^{\circ} \mathrm{C}$. Since other variables than SSS influence the $T_{B}$ signal (sea surface temperature, surface roughness and foam), the accuracy of the SSS measurement will degrade unless these effects are properly accounted for. The main objective of the ESA-sponsored Wind and Salinity Experiment (WISE) field experiments has been the improvement of our understanding of the sea state effects on $T_{B}$ at different incidence angles and polarizations. This understanding will help to develop and improve sea surface emissivity models to be used in the SMOS SSS retrieval algorithms. This paper summarizes the main results of the WISE field experiments on sea surface emissivity at L-band and its application to a performance study of multiangular sea surface salinity retrieval algorithms. The processing of the data reveals a sensitivity of $T_{B}$ to wind speed extrapolated at nadir of $\sim 0.23-0.25 \mathrm{~K} /(\mathrm{m} / \mathrm{s})$, increasing at
\end{abstract}

Manuscript received March 24, 2003; revised September 4, 2003. WISE field experiments were supported by the European Space Agency under ESTEC Contract 14188/00/NL/DC, with contributions from the Spanish R +D National plan under grants CICYT TIC2002-04451-C02-01 and ESP2001-4523-PE. The UPC L-band radiometer was implemented by the Spanish government under grant CICYT TIC99-1050-C03-01

A. Camps, M. Vall-llossera, I. Corbella, N. Duffo, F. Torres, S. Blanch, A. Aguasca, R. Villarino, L. Enrique, J. J. Miranda, and J. J. Arenas are with the Universitat Politècnica de Catalunya, Campus Nord, D4, 08034 Barcelona, Spain (e-mail: camps@tsc.upc.es).

J. Font, C. Gabarró, and A. Julià are with the Institut de Ciències del Mar, CMIMA-CSIC, 08003 Barcelona, Spain.

J. Etcheto, J. Boutin, and S. Contardo are with the LODYC, UPMC, 75252 Paris Cedex 05, France.

V. Caselles, R. Niclós, and R. Rivas are with the Dartimento Termodinàmica, Facultat de Física, Universitat de València, 46100 Burjassot, Spain.

A. Weill is with the CETP, 78140 Vélizy, France.

S. C. Reising is with the Microwave Remote Sensing Laboratory, University Massachusetts at Amherst, Amherst, MA 01003 USA

P. Wursteisen, M. Berger, and M. Martín-Neira are with the European Space Research and Technology Centre, European Space Agency (ESA-ESTEC), 2200 AG Noordwijk, The Netherlands.

Digital Object Identifier 10.1109/TGRS.2003.819444 horizonal $(\mathrm{H})$ polarization up to $\sim 0.5 \mathrm{~K} /(\mathrm{m} / \mathrm{s})$, and decreasing at vertical $(\mathrm{V})$ polarization down to $\sim-0.2 \mathrm{~K} /(\mathrm{m} / \mathrm{s})$ at $65^{\circ}$ incidence angle. The sensitivity of $T_{B}$ to significant wave height extrapolated to nadir is $\sim 1 \mathrm{~K} / \mathrm{m}$, increasing at $\mathrm{H}$-polarization up to $\sim 1.5 \mathrm{~K} / \mathrm{m}$, and decreasing at $\mathrm{V}$-polarization down to $-0.5 \mathrm{~K} / \mathrm{m}$ at $65^{\circ}$. A modulation of the instantaneous brightness temperature $T_{B}(t)$ is found to be correlated with the measured sea surface slope spectra. Peaks in $T_{B}(t)$ are due to foam, which has allowed estimates of the foam brightness temperature and, taking into account the fractional foam coverage, the foam impact on the sea surface brightness temperature. It is suspected that a small azimuthal modulation $\sim 0.2-0.3 \mathrm{~K}$ exists for low to moderate wind speeds. However, much larger values (4-5 K peak-to-peak) were registered during a strong storm, which could be due to increased foam. These sensitivities are satisfactorily compared to numerical models, and multiangular $T_{B}$ data have been successfully used to retrieve sea surface salinity.

Index Terms-Foam, L-band, radiometry, sea salinity retrieval, sea spectrum, waves, wind.

\section{INTRODUCTION}

O EA SURFACE salinity is a key parameter to understand the global ocean circulation and the role of the ocean in the earth's climate. The measurement principles have been known for a long time; however, unlike other oceanographic parameters (surface temperature, ocean color, sea surface height, surface winds) no dedicated space mission has been launched up to now to measure salinity. The main reasons for this are the technological challenges that have to be solved to build and fly an instrument which meets the stringent accuracy requirements, and also achieve a reasonable spatial resolution. Sea surface salinity can be measured by using passive microwave remote sensing at L-band, in the astronomical protected frequency band of 1.400-1.427 MHz. However, this is a compromise between the sensitivity of the brightness temperature to the salinity, small atmospheric perturbations, and reasonable spatial resolution [1]. To provide global observations of ocean surface salinity and soil moisture with a three-day revisit time the European Space Agency (ESA) selected the Soil Moisture and Ocean Salinity (SMOS) mission as the second Earth Explorer Opportunity Mission in May 1999 to be launched in 2007 [2]. Its payload is Microwave Imaging Radiometer 
by Aperture Synthesis (MIRAS), a new polarimetric two-dimensional (2-D) synthetic aperture interferometric radiometer based on the techniques used in radio-astronomy to obtain high angular resolution and avoiding large antenna structures [3]. The radiometer measures the brightness temperature emitted by the earth's ocean surface, which is not isotropic (varies with incidence angle) and which depends on polarization, sea surface salinity and temperature, and surface roughness. The new challenges of SSS retrieval from L-band radiometry and of the SMOS imaging configuration are as follows:

1) low $T_{B}$ sensitivity to $\mathrm{SSS}$, approximately $0.25-0.5 \mathrm{~K} / \mathrm{psu}$;

2) 2-D imaging of the scene, with varying incidence angles from $0^{\circ}$ to $60^{\circ}$ approximately, and varying spatial resolution within the alias-free field of view;

3) open issues concerning the dependence of the brightness temperature due to wind speed and swell (sea roughness);

4) sea foam emissivity at L-band;

5) polarization mixing between vertical and horizontal polarizations due to Faraday rotation and to the relative orientation between the antenna frame and the pixel's local reference frame.

The 2-D imaging capabilities of MIRAS allows the observation under a wide range of incidence angles, from $0^{\circ}$ at nadir to approximately $60^{\circ}$, which corresponds to a brightness temperature range over the ocean at vertical and horizontal polarizations from $50-150 \mathrm{~K}$, with a small dependence on sea salinity and wind speed. Sea surface salinity observations are then obtained indirectly from brightness temperature measurements, provided the perturbing effects can be corrected. The scientific requirements of the sea surface salinity measurement (accuracy, spatial resolution, and revisit time) for a number of oceanographic applications have been determined by an international scientific panel [4] and dedicated SMOS studies [5] and can be summarized as follows:

1) barrier layer effects on tropical Pacific heat flux: $0.2 \mathrm{psu}$, $100 \mathrm{~km}$, and 30 days;

2) halosteric adjustment of heat storage from sea level: $0.2 \mathrm{psu}, 200 \mathrm{~km}$, and 7 days;

3) North Atlantic thermohaline circulation: $0.1 \mathrm{psu}, 100 \mathrm{~km}$, and 30 days;

4) surface freshwater flux balance: $0.1 \mathrm{psu}, 300 \mathrm{~km}$, and 30 days.

The wind-induced roughness and, to a less extent, the sea foam coverage modify the brightness temperatures. They are major error sources in the sea surface salinity retrieval. The determination of the L-band brightness temperatures sensitivities to ocean surface roughness have been addressed through two ESA-sponsored joint experimental field experiments called WISE involving six research teams from Spain (the Universitat Politècnica de Catalunya, prime contractor, the Institut de Ciències del Mar CMIMA-CSIC, and the Universitat de València), France (the Laboratoire d'Océanographie Dynamique et Climatologique, and the Centre d'Études Terrestres et Planétaires), and the United States (the MIRSL, University of Massachusetts, as a guest institution during WISE 2000) in autumn 2000 and 2001 [6]. This paper describes the results of these field experiments and will introduce the results of a subsequent study as- sessing sea surface salinity retrievals from multiangular brightness temperature data.

\section{A. Field Experiment and Instruments Description}

The WISE 2000 and 2001 field experiments took place at the Repsol's Casablanca oil rig, located at $40^{\circ} 43.02^{\prime} \mathrm{N}, 1^{\circ} 21.50^{\prime} \mathrm{E}$, $40 \mathrm{~km}$ away from the Ebro river mouth at the coast of Catalonia, Spain. The sea depth is $165 \mathrm{~m}$, and the sea conditions are representative of the Mediterranean shelf/slope region with periodic influence of the Ebro river fresh water plume. The WISE 2000 data acquisition was from November 25, 2000 to December 18, 2000 and from January 8, 2001 to January 15, 2001, and WISE 2001 from October 23, 2001 to November 22, 2001.

The following instruments were deployed: a fully polarimetric L-band radiometer (UPC, Fig. 1(a), a fully polarimetric Ka-band radiometer (UMass, Fig. 1(b), only in WISE 2000), four oceanographic and meteorological buoys from ICM and LODYC [Fig. 1(c)-(f)], a portable meteorological station (UPC), a stereo-camera from CETP [Fig. 1(g)] to provide sea surface topography and foam coverage, a video camera from UPC mounted on the antenna pedestal [Fig. 1(a)] to provide instantaneous sea surface foam coverage in the radiometer's field of view, a CIMEL infrared radiometer from UV to provide SST estimates, and a subsurface temperature and conductivity sensor hanging from the platform. Additionally, satellite imagery and water samples were acquired.

Fig. 2(a) and (b) shows the location of the instrumentation during WISE 2000 and WISE 2001, respectively. In WISE 2000, the radiometers and stereo-cameras were pointed to the north, in the direction of the dominant winds. However, to avoid radiofrequency interference (RFI) coming from Tarragona city and probably the Barcelona airport, in WISE 2001, the instrumentation was pointed most of the time to the west, except in the late afternoon-early evening when it was pointed to the northeast to avoid Sun reflections. The microwave radiometers and video camera were mounted on a special terrace built to install the radiometers at the $32-\mathrm{m}$ deck that allowed azimuth scans from $80^{\circ}$ $\mathrm{W}$ to $40^{\circ} \mathrm{E}$ and elevation scans from about $25^{\circ}$ incidence angle to an elevation of $55^{\circ}$ over the horizontal, used for sky calibration. The zenith direction was blocked by the upper floors and the helipad. The IR radiometer was mounted on the radiometer pedestal during WISE 2000, and on a handrail at the 28-m deck pointing to the west during WISE 2001. The stereo-cameras were mounted on a handrail at the 28 -m deck. The control room was at the 28-m deck. Fig. 2(c) shows a picture of the north side of the Casablanca oil rig indicating with a circle the position of the radiometer. The instrumentation which was deployed is briefly described below:

- The L-Band Automatic Radiometer (LAURA): LAURA is a fully-polarimetric radiometer designed and implemented at the Department of Signal Theory and Communications of the Technical University of Catalonia (UPC) [7]. The antenna is $4 \times 4$ microstrip patch square array, with a half-power beamwidth of $20^{\circ}$, measured ${ }^{1}$ side lobe levels

\footnotetext{
${ }^{1}$ Antenna pattern measurements performed at the UPC-Department of Signal Theory and Communications Anechoic Chamber: http://www-tsc.upc.es/eef/research_lines/antennas/anechoic_chamber/default.htm
} 


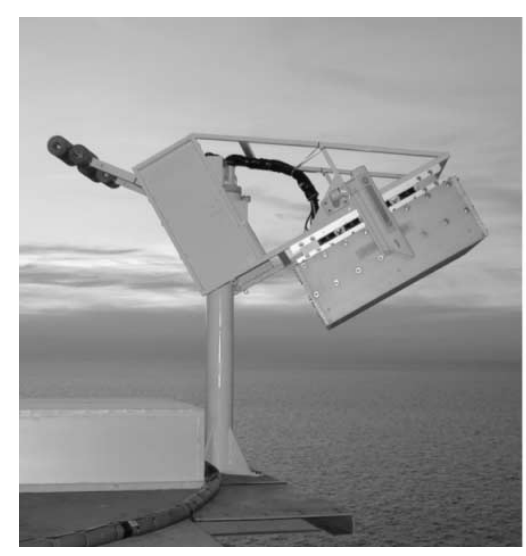

(a)

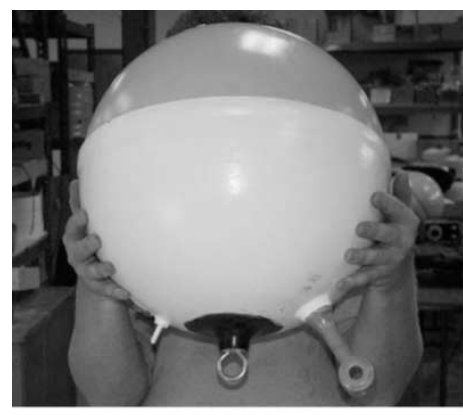

(d)

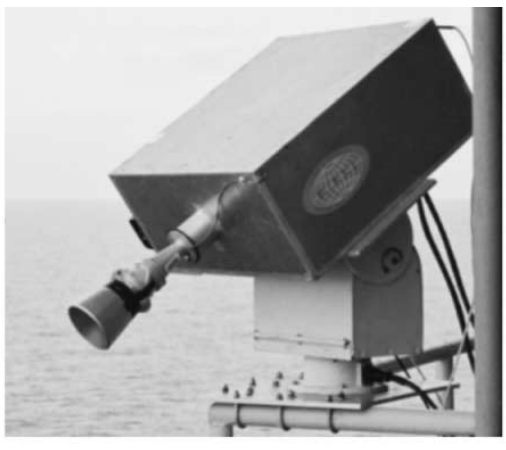

(b)

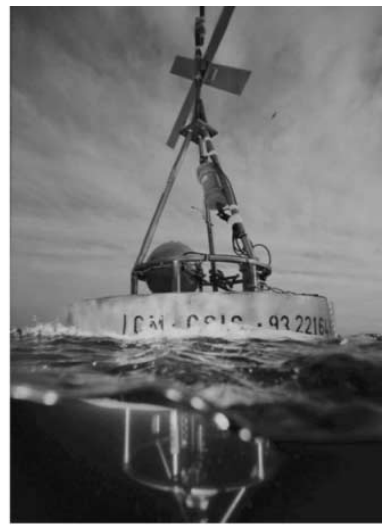

(c)

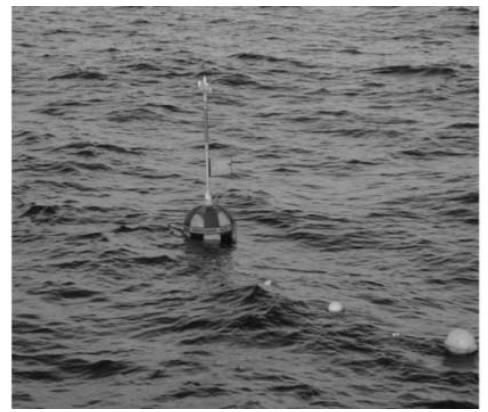

(e)

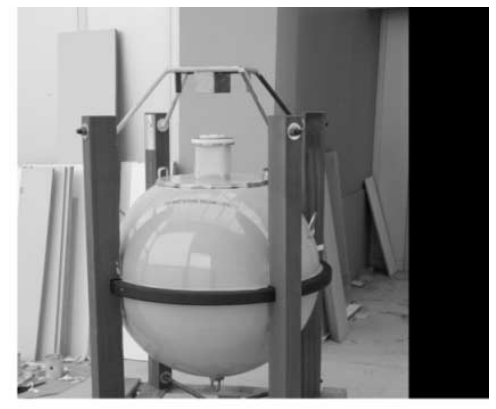

(f)

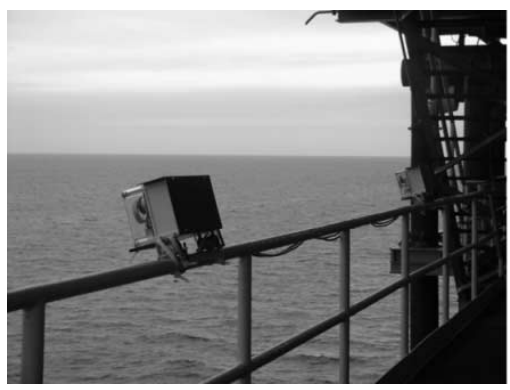

(g)

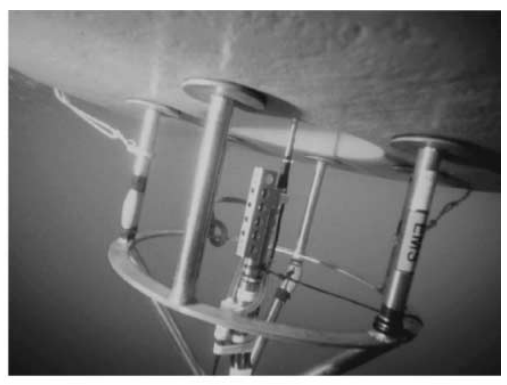

(h)

Fig. 1. Instrumentation deployed during WISE 2000 and 2001. (a) L-band polarimetric radiometric (UPC), video camera (UPC) and IR radiometer IR (UV), (b) Ka-band polarimetric radiometer (UMass, only in WISE 2000), (c) EMS (buoy 1, ICM CMIMA/CSIC), (d) Clearwater SVP buoy (buoy 4, LODYC), (e) Aanderaa CMB3280 (buoy 2, ICM CMIMA/CSIC), (f) Datawell wave buoy (buoy 3, LODYC), (g) pair of stereo-cameras (CETP), and (h) underwater view of the CT recorder in buoy 1 to sample near-surface salinity.

at E- and H-planes of $-19 \mathrm{~dB}$ and $-25 \mathrm{~dB}$, respectively [Fig. 3(a)], a cross-polarization less than $-35 \mathrm{~dB}$ over the whole pattern, and less than $-40 \mathrm{~dB}$ in the main beam [Fig. 3(b)], and a main beam efficiency (MBE) of $96.5 \%$ defined at $2.5 \times$ the half-power beamwidth. The antenna pedestal was oriented by computer-controlled stepmotors and gear-reductions, and the antenna elevation was measured by means of a Seika inclinometer mounted on its back with a resolution $<0.01^{\circ}$ with a $\pm 80^{\circ}$ angular range. The radiometer architecture is based on $2 \mathrm{~L}$-band Dicke radiometers with $I / Q$ down-conversion (Fig. 4). Radiometer's radiometric sensitivity is $0.2 \mathrm{~K}$ for $1 \mathrm{~s}$ integration time. Receiver inputs can be switched between three inputs: 1) the Horizontal (H) and Vertical (V) antenna ports; 2) two matched loads; or 3) a common noise source. The Dicke radiometers are formed by switching receivers' inputs from positions 1) and 2), and performing a synchronous demodulation. The in-phase components of both channels are connected to two power detectors. The third and fourth Stokes parameters are measured with a complex one bit digital correlator.

- Meteorological Stations: Rain rate, atmospheric pressure, relative humidity, and air temperature at 32-m height were measured by the meteorological station of UPC connected to the same computer used by the radiometer. These data were used in the numerical models to estimate the downwelling atmospheric temperature. In addition, an automatic meteorological station installed on the top of the communications tower, $69 \mathrm{~m}$ above the sea level, included the following sensors: wind speed, wind direction, air temperature, air pressure, and relative humidity. These data were recorded and used only as backup information due 

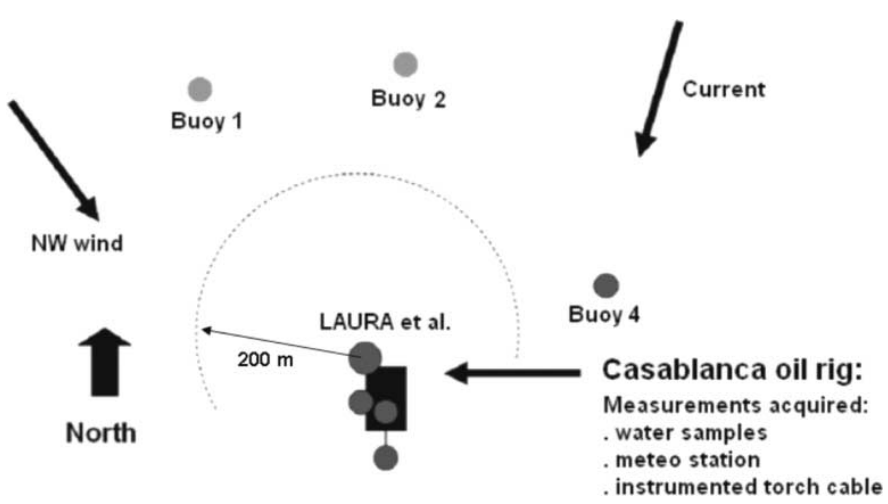

(a)
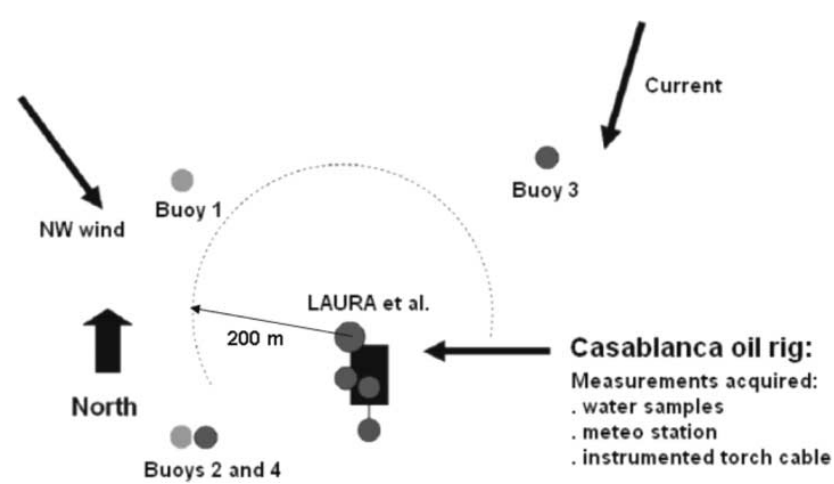

(b)

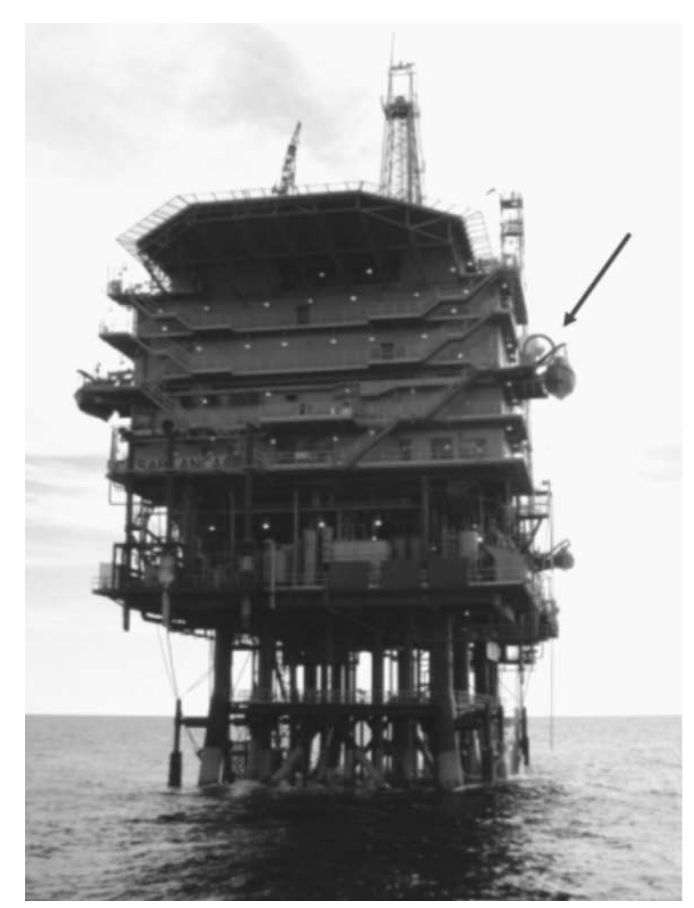

(c)

Fig. 2. Instrumentation and buoy location during (a) WISE 2000 and (b) WISE 2001. (c) North side of the Casablanca oil rig indicating the position of the radiometer.

to the lower resolution and temporal sampling (15 $\mathrm{min})$. However, they were of crucial importance in the data processing of the last week of WISE 2001 due to the loss and fatal damage of the buoys' sensors in the storm on November 15, 2001.

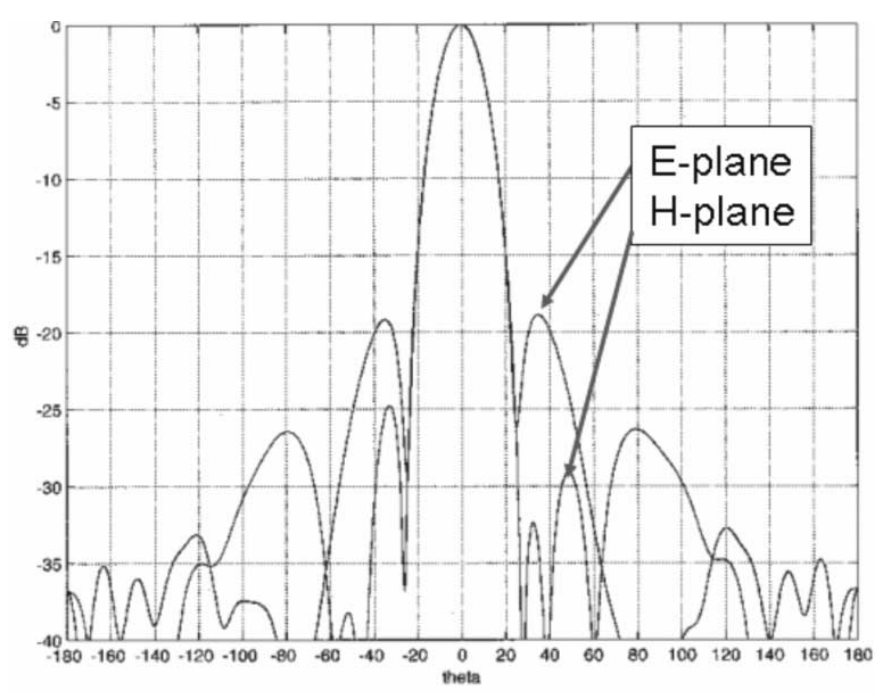

(a)

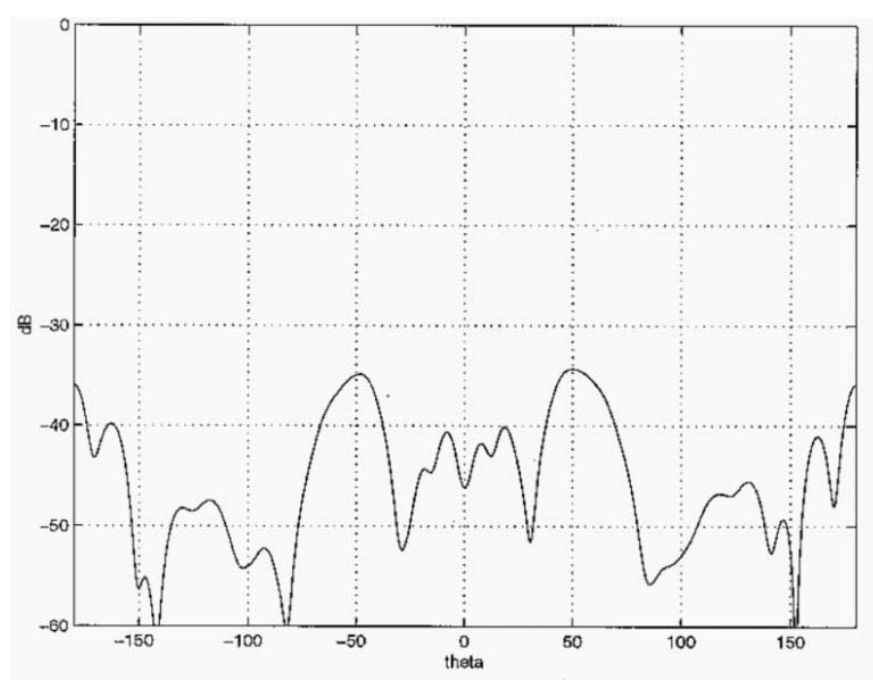

(b)

Fig. 3. Measured L-band radiometer antenna pattern. (a) E- and H-plane cuts $\left(\mathrm{SLL}_{\mathrm{E}-\text { plane }}=-19 \mathrm{~dB}, \mathrm{SLL}_{\mathrm{H}-\text { plane }}=-25 \mathrm{~dB}\right)$. (b) $45^{\circ}$ cross-polar cut $(<-40 \mathrm{~dB}$ in the main beam, $<-35 \mathrm{~dB}$ in the whole pattern).

- Oceanographic Buoys: Four buoys were moored by the oceanographic vessel García del Cid of ICM CMIMACSIC at about 300-500 m away from the Casablanca oil rig, outside the radiometer's field of view, but inside the safety area forbidden to navigation [Fig. 2(a) and (b)]:

BUOY 1: Buoy 1 [Fig. 1(c)] is a floating system holding a conductivity and temperature sensor (SBE37 MicroCAT from Sea-Bird Instruments) placed at $20 \mathrm{~cm}$ below the sea surface [Fig. 1(h)], programmed for a sampling rate of $2 \mathrm{~min}$, plus a Doppler ultrasonic anemometer model 5010-0005 from USONIC (UK) in WISE 2001. Data was stored in a local data storage unit and sent via radio every $30 \mathrm{~min}$ to the oil rig data logger.

BUOY 2: Buoy 2 is a CMB 3280 (Coastal Monitoring Buoy), from Aanderaa Instruments [Fig. 1(e)], moored also on the restricted navigation zone, close 


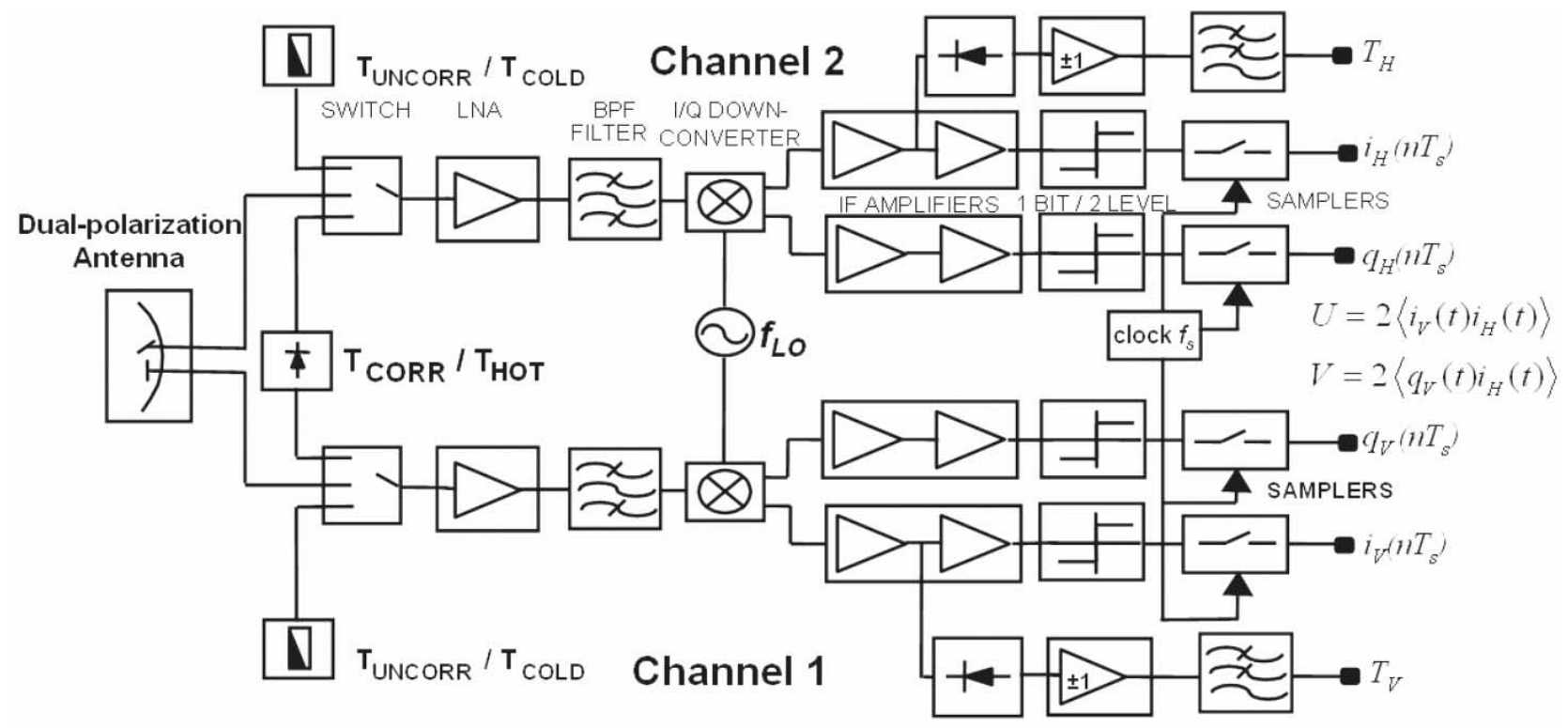

Fig. 4. LAURA's radiometer architecture. Dual-polarization antenna outputs are connected to two Dicke radiometers to estimate the first two modified Stokes parameters $\left(T_{v}\right.$ and $\left.T_{h}\right)$ and to a one-bit/two-level complex digital correlator to estimate the third and fourth Stokes parameters $(U, V)$.

to the oil platform and BUOY 1. It is a solar-powered autonomous buoy that measures meteorological and oceanographic parameters storing the data and conveying it simultaneously to the platform via a real time radio link. The wind speed, wind direction, air temperature, solar radiation, relative humidity (arm at $2.6 \mathrm{~m}$ above the sea surface), wave height $\left(H_{1 / 3}\right)$, and wave period sensors were also programmed also for a sampling rate of $2 \mathrm{~min}$.

BUOY 3: Buoy 3 is a SPEAR-F buoy based on a Datawell accelerometer installed in a waverider 70-cm-diameter sphere [Fig. 1(f)]. Omnidirectional wave buoy measurements are made every $3 \mathrm{~h}$. During the three hours, eight different 200-s records are Fourier transformed and averaged (lowest frequency $=0.025 \mathrm{~Hz}$ ). At the end of the 3-h period, the information is transmitted via the ARGOS system. The information was compressed for transmission to satellite in 14 frequency bands containing a predefined fraction of the variance.

BUOY 4: Buoy 4 is an SVP Clearwater drifter $(16.63-\mathrm{kg}$ buoyancy) that measures water conductivity and temperature, and at about 20-cm depth (depending on the waves) using an FSI conductivity sensor placed on the lower part of the sphere [see buoy and sensors in Fig. 1(d)]. The measurements are performed once per hour. Data were transmitted via the ARGOS system. In WISE 2001, it was attached to buoy 2 for security reasons (in 2000, the small buoy 4 mooring was lost two weeks after deployment).

In WISE 2000, buoy 3 was damaged during the deployment and could not further be used. A new Spear-F buoy was moored during WISE 2001, which remained operational for the whole field experiment. During November 15, 2001, a very strong storm hit the
Catalan coast. The buoy 4 link to buoy 2 broke, and buoy 4 started drifting to the south. It was recovered by a Spanish Coast Guard vessel on November 29. Thus, the conductivity sensor could be recalibrated after the field experiment, and this calibration was used to process the data. The SSS measurements of buoys 1 and 4 agreed by less than 0.07 psu at all times when they measured simultaneously. On November 15, 2001, buoys 1 and 2 also suffered serious damage and, some data were lost, particularly the accurate wind speed measurements.

- Stereo Camera: The system consists of two digital video cameras Canon Powershot $600(832 \times 624$ pixels $)$, spaced $4 \mathrm{~m}$ and located at $28 \mathrm{~m}$ over the sea surface, just below the radiometers terrace [Fig. 1(g)]. The stereo-camera provides sea foam coverage estimates and sea surface topography, by observing the sea surface from an incidence angle under two different views. During WISE 2000, they were pointed to the north, where the radiometers should point most of the time (upwind direction of dominant winds). However, during WISE 2001, they were pointed to the west, as was the radiometer. To avoid sun reflections with this orientation, measurements with the stereo-camera were restricted to the morning. ${ }^{2}$ Systematic measurements coincident with the radiometer were performed every day from 9 A.M. to 10 A.M. to compare the evolution of $T_{B}$ with sea state and foam.

- Video Camera: A video camera $(8.5 \mathrm{~mm}$ lens, auto-iris, resolution $512 \times 582$ pixels, field of view: $35.6^{\circ}$ in horizontal and $25.2^{\circ}$ in vertical) was mounted in the antenna pedestal [Fig. 1(a)] to provide an instantaneous view of the sea surface being measured by the radiometer. Images were stored every second. The analysis of the images re-

\footnotetext{
${ }^{2}$ The L-band radiometer cannot make measurements in this direction in the afternoon/evening either.
} 
stricted to a $20^{\circ}$ field of view (coincident with the antenna beamwidth) has been used to evaluate the sea foam coverage as a function of wind speed (by analysis of the image histograms). By this, sea foam emissivity could be estimated by comparing the instantaneous sea foam coverage and the instantaneous brightness temperatures $\left(T_{v}\right.$ and $T_{h}$ ), and erroneous measurements could be identified, e.g., when the security vessel that made circles around the platform or even when whales passed through the antenna beam.

- Infrared Radiometer: The CIMEL CE 312 thermal-infrared radiometer is a four-band radiometer covering 8-13 $\mu \mathrm{m}, 11.5-12.5 \mu \mathrm{m}, 10.5-11.5 \mu \mathrm{m}$, and 8.2-9.2 $\mu \mathrm{m}$, with radiometric sensitivities $0.008,0.05,0.05$, and $0.05 \mathrm{~K}$; and radiometric accuracies $\pm 0.10 \mathrm{~K}, \pm 0.12 \mathrm{~K}$, $\pm 0.09 \mathrm{~K}$, and $\pm 0.14 \mathrm{~K}$, at $20^{\circ} \mathrm{C}$, with a field of view of $10^{\circ}$. It has been used to provide sea surface temperature estimates, simultaneous with LAURA's measurements. During WISE 2000, the CE 312 was mounted on the LAURA pedestal to observe the sea surface with identical conditions (zenith and azimuth angles). However, since the CE 312 read-outs are brightness temperatures, these data have to be corrected for atmospheric and sea emissivity effects, before being compared to SST estimates derived from the AVHRR imagery and the oceanographic buoys. To overcome this conflict, and taking into account that the best SST estimates were found for the lowest observation angles, in WISE 2001 the IR radiometer was mounted alone on a handrail pointing to the sea (west direction) with an observation angle of $25^{\circ}$, and the downwelling sky radiance was simulated using the MODTRAN 4 radiative transfer code.

- Additional Oceanographic Data: To monitor the top layer vertical stratification, a second SBE37 MicroCAT was installed at $-5 \mathrm{~m}$, hanging in a cable from the gas torch of the platform. During WISE 2000 an acoustic Doppler current meter (Aanderaa RCM9) was also hung at $-2 \mathrm{~m}$, for air-sea speed comparison, but in 2001 it was removed as the data were of no use. To check for possible drifts in the conductivity sensors, water samples were taken when deploying and recovering the buoys for later salinity determination with a Guildline Autosal salinometer. These instruments, when used under strictly controlled room conditions, can provide very accurate salinity estimates by comparing the relative conductivity of the sample to a reference standard water of $35.0000 \mathrm{psu}$. The absolute accuracy is given to $0.002 \mathrm{psu}$ and the resolution $0.0002 \mathrm{psu}$. No drifts were detected.

\section{RADIOMETRIC DATA ACQUISITION AND CALIBRATION}

To avoid picking up radiation from the upper decks, the heliport or the radiometers' terrace, the angular scans were limited in elevation from $25^{\circ}$ (limited by the terrace) to $145^{\circ}$ (limited by the heliport), and in azimuth from $260^{\circ}$ and $20^{\circ}$ referred to the north, clockwise (limited by the oil rig). Taking into account these limitations, three different types of measurements were performed: incidence angle scans, azimuth angle scans, and fixed positions.
- Incidence angle scans: Scans were performed in the range of azimuth angles from $290^{\circ}$ to $20^{\circ}$ from the north at five or ten incidence angles: $\theta_{i}=25^{\circ}, 35^{\circ}, 45^{\circ}, 55^{\circ}$ and $65^{\circ}, 20 \mathrm{~min} /$ position or $\theta_{i}=25^{\circ}, 30^{\circ}, 35^{\circ}, 40^{\circ}$, $45^{\circ}, 50^{\circ}, 55^{\circ}, 60^{\circ}$ and $65^{\circ}, 5 \mathrm{~min} /$ position. Data acquisition started with a calibration sequence (see below), after which measurements started at 1-s sampling rate. At the end of the sequence a second full calibration was made to check system's stability.

- Azimuth angle scans: Scans were performed in the range of incidence angles from $25^{\circ}$ to $65^{\circ}$ at different azimuthal positions: $\phi_{i}=260^{\circ}, 290^{\circ}, 320^{\circ}, 350^{\circ}$, and $20^{\circ}$, with respect to north, $5 \mathrm{~min} /$ position. Calibrations were performed at the beginning and at the end of each complete scan.

- Fixed position: The radiometer was pointed to $\theta_{i}=44^{\circ}$ and $\phi_{i}=0^{\circ}$ (north) or $270^{\circ}$ (west), during WISE 2000 and 2001, respectively. In these positions, the antenna footprint and that of the stereo-camera were coincident. The measurement process was the same than in the former two cases: calibration, $1 \mathrm{~h}$ of measurements, and new calibration. In this type of scans, measurements were not averaged.

Radiometric calibration is the process to pass from measurements (millivolts and correlator counts) to Stokes parameters (Kelvin). The full calibration process is carried out at the beginning and at the end of each scan or fixed position measurement. Voltage samples used for calibration and measurements are first visually inspected to eliminate high peaks, evident sign of potential RFI. The interference-free samples are then averaged to reduce noise variance. The vertical and horizontal brightness temperatures are measured with the dual-polarization Dicke radiometer. The third and fourth Stokes parameters are measured with a digital complex cross correlator as $U \alpha 2 \Re e\left[\left\langle E_{v} E_{h}^{*}\right\rangle\right]$ and $V \alpha \operatorname{Im} m\left[\left\langle E_{v} E_{h}^{*}\right\rangle\right]$. The calibration of the Dicke radiometer and the cross correlator are described below.

- Calibration of Dicke radiometers: In the Dicke radiometers (horizontal and vertical channels), the relationship between the output voltage $\left(V_{\text {out }}\right)$ and the antenna temperature $\left(T_{A}\right)$ is a straight line $V_{\text {out }}=a\left(T_{\text {ref }}-T_{A}\right)+b$, determined from - at least - two points: a hot and a cold load. The higher their temperature difference and having them cover the measurement antenna temperature range, the smaller the error. In WISE, the sky was used as cold load ( $T_{A \text {,cold }} \approx 6-7 \mathrm{~K}$, or even higher if pointing to the galaxy), and a microwave absorber at ambient temperature as "hot load" ( $\left.T_{A \text {,hot }} \approx T_{\text {physical }}\right)$. Since it was not possible to point the antenna directly to zenith due to radiation from upper decks, it was then oriented to $\theta=55^{\circ}$ elevation angle and $\phi_{i}=320^{\circ}$ during 4 min. $T_{A \text {,cold }}$ was computed integrating the resulting brightness temperature contributions (atmospheric, cosmic, and galactic noises), weighted by the antenna pattern. The cosmic noise is constant, and its value is $2.7 \mathrm{~K}$. The galactic noise was computed taking into account the geographic position of the 
rig, the date, and time, the antenna orientation, the antenna pattern, and the 1420-MHz galactic noise map [8], [9]. Atmospheric noise was accounted for using a low-frequency approximation of Liebe's atmospheric propagation model [10] that takes into account the atmospheric pressure, temperature, and relative humidity as input parameters. The "hot load" is a $90 \times 90 \mathrm{~cm}$ microwave absorber $45 \mathrm{~cm}$ thick, with return losses at L-band $<-30 \mathrm{~dB}$, enclosed in an hermetically closed polystyrene box at ambient temperature, measured by two temperature sensors. "Hot load" measurements last $4 \mathrm{~min}$. The radiometer was stable to $\sim 0.1 \mathrm{~K}$ in $\sim 100 \mathrm{~min}$.

- Calibration of the One-Bit/Two-Level complex correlator: The calibration of a complex correlation radiometer used is described in [11]. Offset calibration was performed by switching receivers' front-end to a matched load. The measured correlation values were then subtracted from subsequent measurements. In-phase calibration was performed by switching receivers' front-end to a common noise source and measuring the phase of the complex correlation. Due to technical problems in WISE 2001, the correlator block was disconnected. Therefore, $U$ and $V$ measurements are only available for WISE 2000 data. It was found [12] that the amplitude of $U$ is rather small $\sim 0.5 \mathrm{~K}$ peak to peak, and that of $V$ is negligible. ${ }^{3}$

Correction of other perturbing factors is required to obtain the Stokes parameters from the sea surface from the measured Stokes parameters:

- Downwelling radiation scattered by the sea surface: The total downwelling temperature is computed applying the same procedure as for the cold load calibration. This is an important term, since the galactic noise contribution averaged by LAURA's antenna pattern can vary as much as $3-4 \mathrm{~K}$ during a scan depending of the time and/or direction where the antenna is pointing. Then, a sea surface reflection coefficient is computed as $\rho_{h, v} \approx 1-e_{h, v}\left(\mathrm{SST}, \mathrm{SSS}, U_{10}\right)$, where $U_{10}$ is the $10-\mathrm{m}$ height wind speed, and it is assumed that all the downwelling radiation comes from the direction of specular reflection. The scattered temperature $T_{S C h, v}^{\prime}=T_{D N h, v} \cdot \rho_{h, v}$ is then subtracted from the calibrated brightness temperatures. Strictly speaking, since downwelling radiation from all directions is collected by the antenna, more complex models must be used to compute the bistatic scattering coefficients, and then the scattered temperature, however differences are minor. Taking into account the radiometer height, no further atmospheric corrections need to be applied.

- Antenna finite beamwidth effects: LAURA's antenna halfpower beam-width is $20^{\circ}$. The spatial averaging caused by the finite antenna beamwidth makes the measured Stokes parameters $\hat{T}_{h}, \hat{T}_{v}, \hat{U}, \hat{V}$ to be a linear combination of the true ones $T_{h}, T_{v}, U, V$.

\footnotetext{
${ }^{3}$ In spaceborne systems, Faraday rotation could be corrected from the measured value of $U$, which almost completely due to the rotation of the polarization planes, since $U_{\text {sea }} \approx 0$
}

TABLE I

Number of Data Points For EACH InCidence ANGLE AND POLARIZATION IN WISE 2000

\begin{tabular}{cccccc}
\hline$\theta_{i}=$ & $25^{\circ}$ & $\theta=35^{\circ}$ & $\theta=45^{\circ}$ & $\theta=55^{\circ}$ & $\theta=65^{\circ}$ \\
H-pol & 20 & 23 & 29 & 14 & 8 \\
V-pol & 100 & 74 & 98 & 102 & 100 \\
\hline
\end{tabular}

\section{SEa Surface L-BAnd BRightness TEMPERATURE OBSERVATIONS}

The main goal of the WISE field experiments was to determine the brightness temperature sensitivity to wind speed at different incidence angles. During WISE 2000 atmospheric conditions were mostly stable and most data was acquired under low to moderate wind conditions. Data files were read, data points sorted, screened, and points farther away from $\pm 4 \sigma$ from the linear regression were suspected to be wrong or corrupted by RFI and were eliminated.

- Brightness temperature sensitivity to wind speed: To derive the brightness temperature sensitivity to the $10-\mathrm{m}$ height wind speed $\left\langle U_{10}\right\rangle$, a brightness temperature variation $\Delta T_{B \text { wind, } p}$ is computed from the flat surface emissivity model

$$
\begin{array}{r}
T_{B, p}\left(\theta_{i}, \mathrm{SST}, \mathrm{SSS}, U_{10}\right)=T_{B \text { Fresnel } p}\left(\theta_{i}, \mathrm{SST}, \mathrm{SSS}\right) \\
+\Delta T_{B \text { wind }, p}\left(\theta_{i}, U_{10}\right)
\end{array}
$$

where

$T_{B \text { Fresnel } p}\left(\theta_{i}, \mathrm{SST}, \mathrm{SSS}\right)=\mathrm{SST} \cdot e_{p}\left(\theta_{i}, \mathrm{SST}, \mathrm{SSS}\right)$

is the brightness temperature of a flat sea surface and

$$
e_{p}\left(\theta_{i}, \mathrm{SST}, \mathrm{SSS}\right)=1-\left|\Gamma_{p}\left(\theta_{i}, \mathrm{SST}, \mathrm{SSS}\right)\right|^{2}
$$

is the emissivity computed from the Fresnel field reflection coefficient at $p$-polarization using the Klein and Swift model [13]. ${ }^{4}$ The linear regression of the $\Delta T_{B \text { wind, } p}$ points versus $U_{10}$ at each incidence angle and polarization was obtained. The slope of this linear regression is the sensitivity to wind speed.

Unfortunately, due to the high RFI encountered during WISE 2000 , the number of remaining data points is not large (Table I) and the associated error bars are large. As it can be appreciated, the number of data points is much smaller at horizontal polarization because of the RFI, and decreases dramatically at higher incidence angles, which induces larger uncertainties in the estimation of the wind speed sensitivity. Part of the error bars are due to the uncertainty in the wind speed estimation, its natural

\footnotetext{
${ }^{4} \mathrm{New}$ measurements of the dielectric constant at L-band have been performed during the spring-summer 2002 using a water-filled waveguide [15]. For example, the water dielectric constant at $35 \mathrm{psu}$ and at $5{ }^{\circ} \mathrm{C}, 15{ }^{\circ} \mathrm{C}$, and $25^{\circ} \mathrm{C}$ is $75.52+j 41.76,72.03+j 53.95$, and $69.24+j 66.83$ using the Ellison et al. model [14], $75.84+j 51.95,73.57+j 61.28$, and $70.68+j 72.30$ using the Klein and Swift model, and $76.46+j 53.75,73.93+j 63.61$, and $71.17+j 75.26$ using the Blanch and Aguasca model. The new Blanch and Aguasca model is in closer agreement with the Klein and Swift model, than the Ellison et al. one, and it exhibits a more linear trend versus temperature than the Klein and Swift one. The authors believe that part of the residual error $\Delta T_{B \text { wind }, p}=\left(\theta_{i}, 0\right) \neq 0$ may be partially due to an incorrect estimation of the term $T_{B \text { Fresnel, } p}\left(\theta_{i}, \mathrm{SST}, \mathrm{SSS}\right)$.
} 
Sea surface salinity (psu)

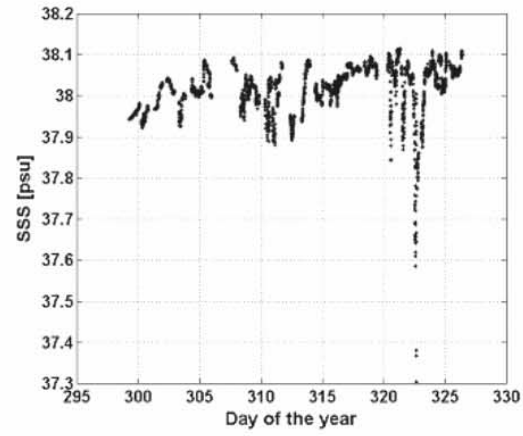

Sea surface temperature $\left({ }^{\circ} \mathrm{C}\right)$

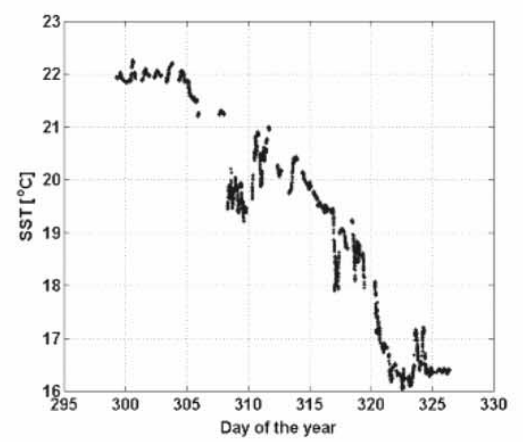

Wind speed at $10 \mathrm{~m}(\mathrm{~m} / \mathrm{s})$

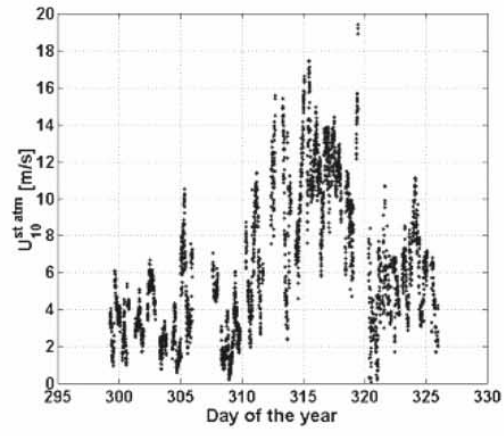

Air temperature $\left({ }^{\circ} \mathrm{C}\right)$

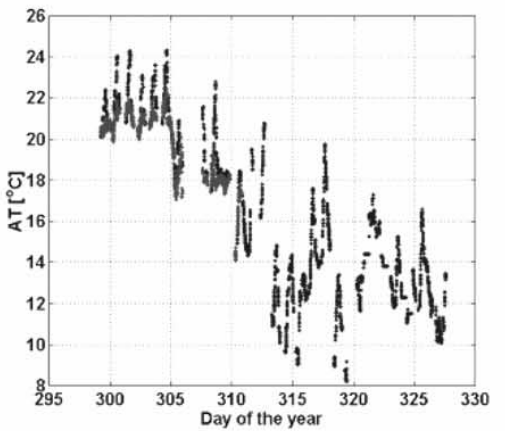

Significant wave height $(\mathrm{m})$

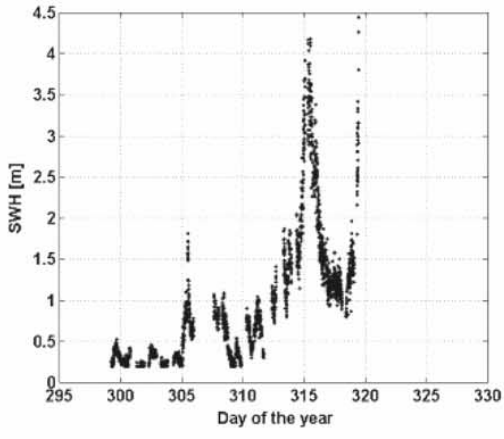

Wave period (s)

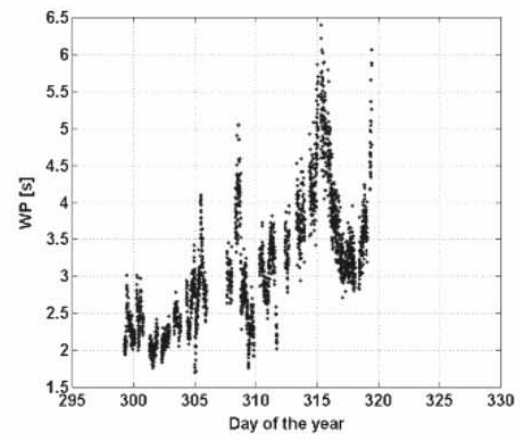

Fig. 5. Main oceanographic and meteorological parameters during WISE 2001. Significant wave height is defined as the average of the highest third of the waves. Air temperature measured by buoy (until day of year 311, light gray) and by meteorological station at 32-m deck (until day of year 327, dark gray) Note the unstable atmospheric conditions from November 10-16, 2001 (days of year: 314-320).

variability and the errors in computing $U_{10 \text { meteo }}=U_{10}\left(U_{69}\right)$ and $U_{10 \text { buoy }}=U_{10}\left(U_{2.6}\right): \sigma_{U 10}$ meteo- $U 10$ buoy $=1.8 \mathrm{~m} / \mathrm{s}$.

Results shown in Fig. 13 from [16] are in reasonable agreement with Hollinger [17] and Swift [18] measurements, with reduced error bars, and give an extrapolated sensitivity at nadir of $\sim 0.22 \mathrm{~K} /(\mathrm{m} / \mathrm{s})$. The sensitivity to $U_{10}$ with incidence angle increases at horizontal polarization, while it decreases at vertical polarization, and around $\theta_{i} \sim 60^{\circ}$, the brightness temperature at vertical polarization becomes insensitive to wind speed. However, the fact that at low incidence angles, the sensitivity of $T_{v}$ to wind speed is larger than that of $T_{h}$-although within the error bars-is a behavior that is neither predicted by models nor present in Hollinger's [17] measurements.

During WISE 2001, the meteorological and oceanographic conditions reached the most extreme values ever recorded on the platform in 20 years. Fig. 5 shows a summary of the main oceanographic and meteorological parameters. During more than one third of the field experiment wind speed exceeded 10 $\mathrm{m} / \mathrm{s}$, reaching more than $25 \mathrm{~m} / \mathrm{s}$, during the strongest storm. Peak waves were larger than $12 \mathrm{~m}$ and destroyed the 7-m deck of the oil rig. In this storm, the memory of buoy 2 and the ultrasonic anemometer on buoy 1 were destroyed, and from this date to the end of the field experiment, the only available wind speed data was $U_{69}$ from the oil rig meteorological station. The measured sea surface salinity was very stable during the whole field experiment, around 38 psu, except on November 18 due to an intense rain event. The sea surface temperature showed the start of the cooling from the warm summer value
TABLE II

Number of Data Points FOR EACH INCIDENCE ANGLE AND POLARIZATION IN WISE 2001

\begin{tabular}{cccccccccc}
\hline$\theta_{i}=$ & $25^{\circ}$ & $30^{\circ}$ & $35^{\circ}$ & $40^{\circ}$ & $45^{\circ}$ & $50^{\circ}$ & $55^{\circ}$ & $60^{\circ}$ & $65^{\circ}$ \\
H-pol & 143 & 36 & 232 & 35 & 478 & 33 & 348 & 36 & 125 \\
V-pol & 305 & 34 & 532 & 56 & 656 & 57 & 511 & 49 & 190 \\
\hline
\end{tabular}

$22^{\circ} \mathrm{C}$ down to $16^{\circ} \mathrm{C}$. At the beginning of the field experiment, the atmosphere was stable, but quickly changed to unstable conditions $\left(T_{\text {air }}-T_{\text {sea }} \approx-6^{\circ} \mathrm{C}\right.$ to $\left.-12{ }^{\circ} \mathrm{C}\right)$. Since wind speed measurements have to be referred from 2.6 or $69 \mathrm{~m}$ ( $U_{69}$ only wind data from November 15-22, 2001) to 10-m height, and the atmospheric conditions were quite unstable, atmospheric instability corrections were applied [19]. ${ }^{5}$

The derivation of the brightness temperature sensitivity to wind speed follows the same steps as for WISE 2000, but the number of data points is much larger (Table II), since incidence angles at $30^{\circ}, 40^{\circ}, 50^{\circ}$, and $60^{\circ}$, corresponding to the afternoon-evening measurements pointing to the northeast, are also available. Results are presented in Fig. 6(a) and (b). It shows the plots of the brightness temperatures deviation due to wind $\left(\Delta T_{B \text { Wind }, \rho}\right)$ at horizontal (upper row) and vertical (central row) polarizations versus the wind speed at $10 \mathrm{~m}$, for incidence angles from $25^{\circ}$ to $65^{\circ}$, in $5^{\circ}$ steps. The solid line in each plot represents the regression line and the dashed ones the $\pm 50 \%$

\footnotetext{
${ }^{5}$ When both $U_{2.6}$ and $U_{69}$ data were available the correlation between them was 0.88 . After November 15, 2001 wind speed was lower than $10 \mathrm{~m} / \mathrm{s}$, and atmospheric instability corrections should be lower.
} 
(a)
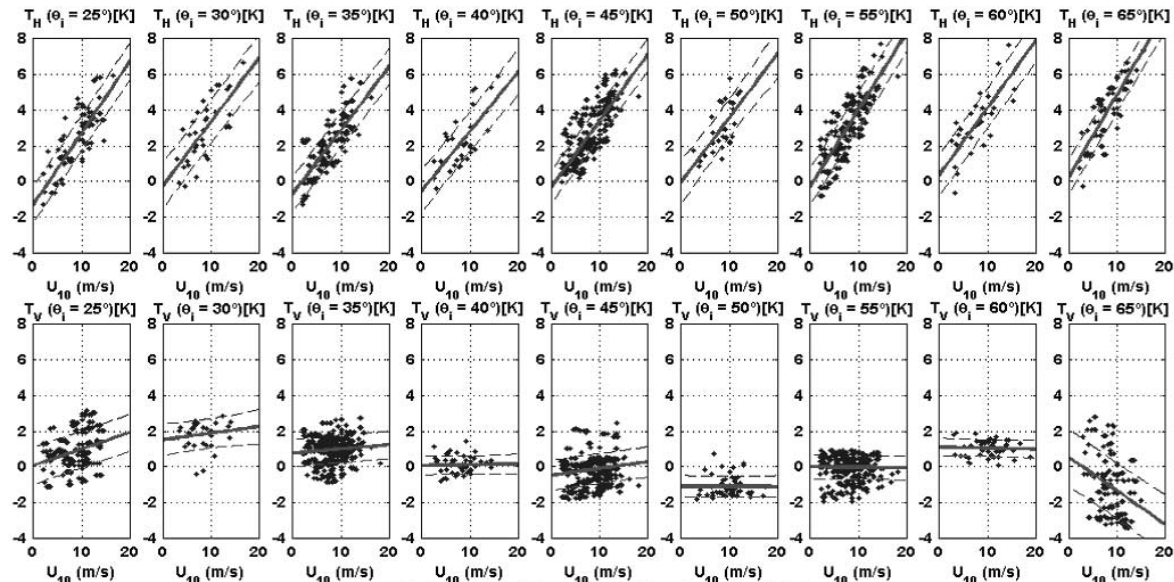

(b)

(c)

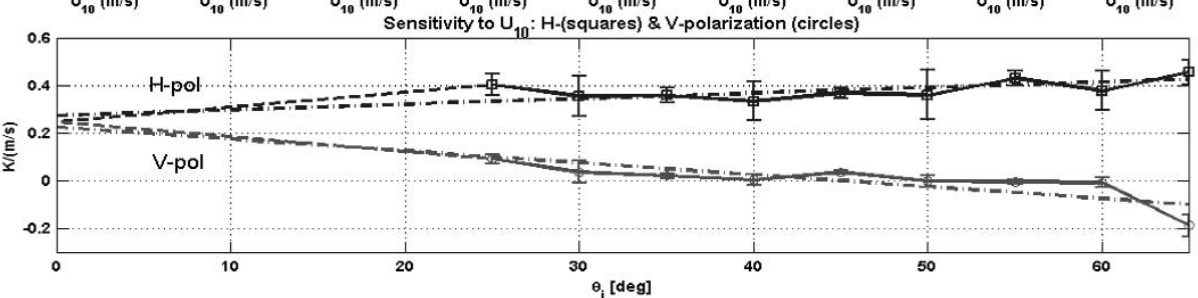

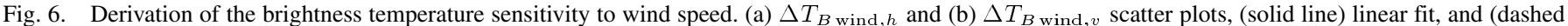
lines) percentile $50 \%$ as a function of wind speed for incidence angles from $25^{\circ}$ to $65^{\circ}$. (c) Derived $T_{B}$ sensitivity to wind speed as a function of (solid line) polarization and incidence angle, associated $\pm 1 \sigma$ error bars, and (dashed lines) linear fit . All data points used.

percentile ones. Each point is the result of averaging the instantaneous measurements $(\tau=1 \mathrm{~s})$ during $5 \mathrm{~min}$. Note that for $U_{10}=0 \mathrm{~m} / \mathrm{s}, \Delta T_{B \text { wind, } v}$ is positive at $30^{\circ}, 35^{\circ}$, and $60^{\circ}$, and negative at $45^{\circ}$ and $50^{\circ}$, which can be due to a calibration error and/or inaccuracies in the dielectric constant model used to compute $T_{B, \text { Fresnel, } \rho}\left(\theta_{j}\right.$, SST, SSS $)$. The solid line in Fig. 6(c) shows the plot of the slope of each regression line [solid lines in Fig. 6(a) and (b)] as a function of the incidence angle, which corresponds to the average sensitivity to wind speed in Kelvin per (meter per second) $[\mathrm{K} /(\mathrm{m} / \mathrm{s})]$ at horizontal and vertical polarizations. The dashed lines in Fig. 6(a) and (b) are the 50\% percentile lines, from which the $\pm 1 \sigma$-error bars in Fig. 6(c) have been computed. A linear fit of these values (Fig. 6(c), dashed line) leads to the following relationships and correlation coefficients:

$$
\begin{array}{rlrl}
\Delta T_{h} \approx 0.23\left(1+\frac{\theta_{i}}{70^{\circ}}\right) U_{10}, & & r_{h}=0.74 \\
\Delta T_{v} \approx 0.23\left(1-\frac{\theta_{i}}{50^{\circ}}\right) U_{10}, & r_{v}=0.89 .
\end{array}
$$

The extrapolated sensitivity at nadir is

$$
\frac{\Delta T_{B, p}\left(\theta_{i}=0^{\circ}\right)}{\Delta U 10} \approx 0.23 \mathrm{~K} /(\mathrm{m} / \mathrm{s})
$$

If [19] is used to try to correct for atmospheric instability when estimating the $10-\mathrm{m}$ wind speed from $69-$ or $2.6-\mathrm{m}$ height wind speed measurements, the resulting brightness temperature sensitivity to wind speed at nadir is slightly higher, and the correlation coefficients of the linear fits increase $\left(r_{h}=0.92, r_{v}=\right.$ $0.90)$

$$
\frac{\Delta T_{B, p}\left(\theta_{i}=0^{\circ}\right)}{\Delta U_{10}} \approx 0.25 \mathrm{~K} /(\mathrm{m} / \mathrm{s})
$$

At this point, it should be noted that the incidence angles $30^{\circ}$, $40^{\circ}, 50^{\circ}$, and $60^{\circ}$ have fewer points and less scatter because they were measured pointing only to the northeast. Measurements at incidence angles $25^{\circ}, 35^{\circ}, 45^{\circ}, 55^{\circ}$, and $65^{\circ}$ have more points and larger scatter because they were measured pointing at all azimuth angles, and these measurements may be more affected by wave reflections in the structure of the platform.

Since there are different numerical models, different sea surface roughness characterizations, and different sea foam emission and coverage models [20], the interpretation of these results with numerical models is not straightforward. To illustrate this issue, Fig. 7 shows the brightness temperature sensitivity to wind speed as a function of wind speed and incidence angle computed with the small slope approximation (SSA) method for two different sea spectra: Durden and Vesecky [21] and Elfouhaily et al. [22], both of them multiplied by two [20]. There is no physical foundation to the fact that the sea spectrum needs to be multiplied by two, specially for the Elfouhaily et al.spectrum, the only one satisfying the Cox and Munk [23] measured sea surface slopes pdf. However, the predicted sensitivities [20] using the spectra as defined in [21] and [22] are a factor of two lower than the measured ones, in agreement with other observations at 19 and $37 \mathrm{GHz}$, which suggests that the extra factor of two is correct. In Fig. 7, the following differences can be appreciated.

- The sensitivity using the Durden and Vesecky spectrum is lower than using the one by Elfouhaily et al.

- The sensitivity computed using the Elfouhaily et al. spectrum exhibits an anomalous behavior: very high at low wind speeds (and high incidence angles), decreasing very quickly with wind and becoming negative up to midincidence angles, then increasing and stabilizing above $7-8 \mathrm{~m} / \mathrm{s}$. On the other hand, the sensitivity computed 


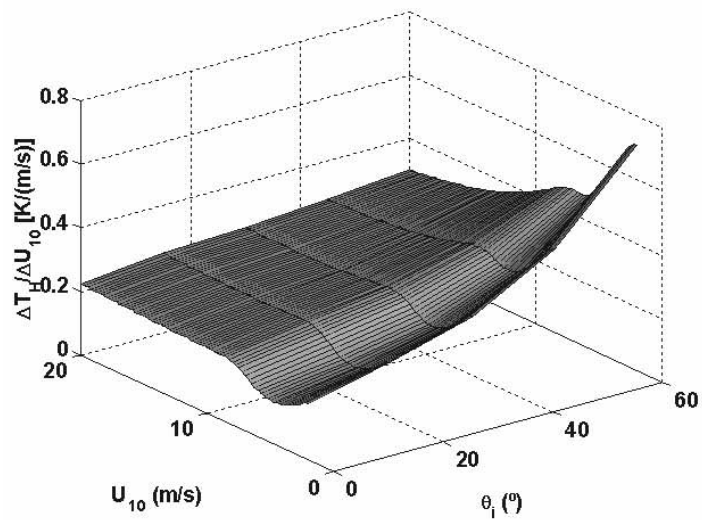

(a)

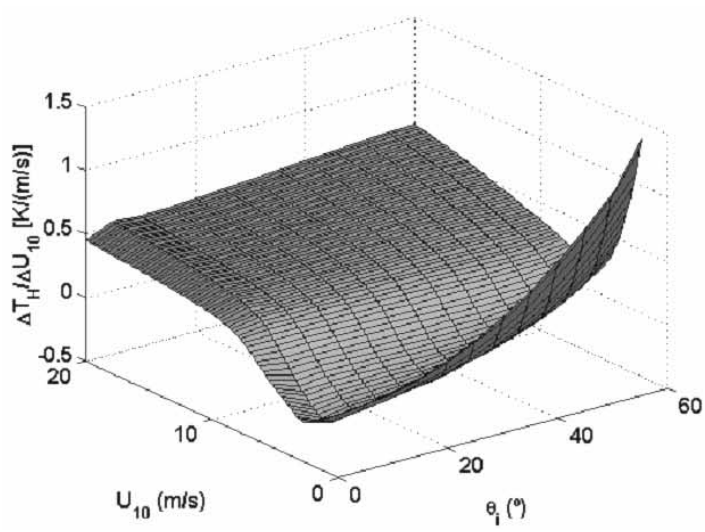

(c)

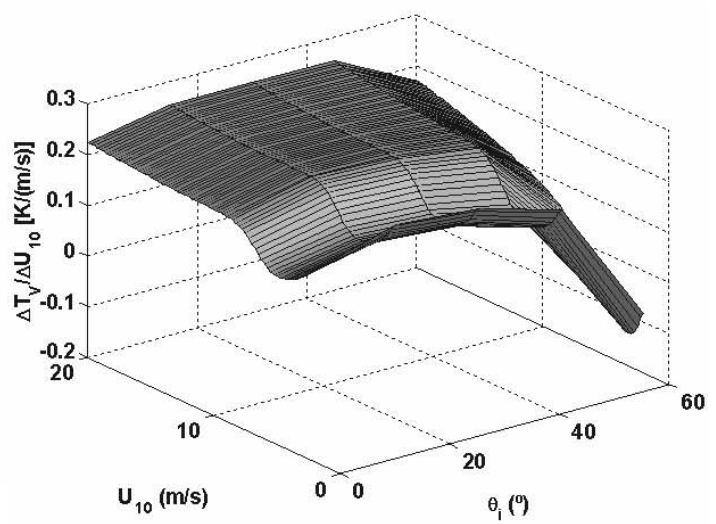

(b)

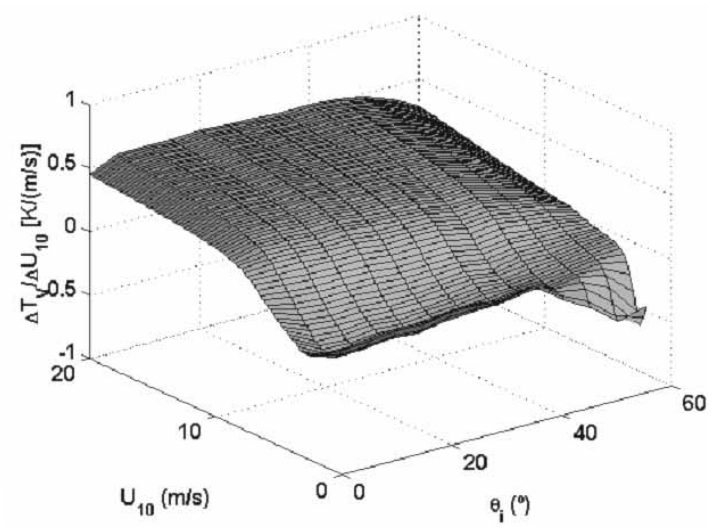

(d)

Fig. 7. Predicted wind speed sensitivity using the SSA method and (a), (b) Durden and Vesecky's spectrum times two [21] or (c), (d) Elfouhaily et al.'s spectrum times two [22] at (a), (c), horizontal and (b), (d), vertical polarizations.

using Durden and Vesecky spectrum is more monotonic, and although it does exhibit a small decrease at low wind speeds, it never becomes negative.

- At vertical polarization, the sensitivity computed with Durden and Vesecky's spectrum exhibits a larger variation with incidence angle than using Elfouhaily et al.'s spectrum, in better agreement with experimental evidence.

The intercomparison of Figs. 6 and 7 requires first the weighting of the predicted sensitivities (Fig. 7) by the histogram of measured $U_{10}$ during WISE 2001. Unfortunately, this intercomparison does not show a good agreement. Part of the disagreement seems to be due more to the lack of accuracy of the sea spectra model, specially at low wind speeds (highly nonmonotonic sensitivities at low wind speeds, Fig. 7), than to the numerical method used SSA (see study with other numerical methods in [20]). Since $45 \%$ of the measurements were performed with wind speeds in the range $0-5 \mathrm{~m} / \mathrm{s}, 34 \%$ in the range $5-10 \mathrm{~m} / \mathrm{s}$, and only $21 \%$ in the range $>10 \mathrm{~m} / \mathrm{s}$, it is clear that an error in the computed sensitivities at low winds has a very large impact in the weighted average. Fig. 8 shows the weighted average of the brightness temperatures sensitivities [H- and V-polarizations, no foam (solid line), with WISE foam emissivity (dashed line)] to wind speed by the WISE 2001 wind speed histogram $\left(U_{10}>2 \mathrm{~m} / \mathrm{s}\right)$ for the Durden and Vesecky spectrum times two, and the Elfouhaily et al. spectrum times two. In both cases, the behavior of the brightness temperature sensitivities to wind speed agrees with the measured one. To check this point, WISE 2001 data was reprocessed retaining only data points corresponding to $10-\mathrm{m}$ wind speeds larger than $2 \mathrm{~m} / \mathrm{s}$ (with atmospheric instability correction). The linear interpolation of the estimated slopes is

$$
\begin{aligned}
& \Delta T_{h} \approx 0.25\left(1+\frac{\theta_{i}}{118^{\circ}}\right) U_{10}, r_{h}=0.79 \\
& \Delta T_{v} \approx 0.25\left(1-\frac{\theta_{i}}{45^{\circ}}\right) U_{10}, r_{v}=0.90 \text { for } U_{10} \geq 2 \mathrm{~m} / \mathrm{s} .
\end{aligned}
$$

The extrapolated sensitivity at nadir is $0.25 \mathrm{~K} /(\mathrm{m} / \mathrm{s})$, slightly larger than in (5) and the same as in (6), although the model predicts a more constant behavior with the incidence angle.

- Instantaneous brightness temperature: Inspection of the brightness temperature time series revealed that the amplitude of $T_{B}(t)$ increases with wind speed. Fig. 9(a) and (b) shows the brightness temperature standard deviation of each measurement at $\mathrm{H}$ - and $\mathrm{V}$-polarizations as a function of wind speed for incidence angles from $25^{\circ}$ to $65^{\circ}$. For better intercomparison, all plots have been drawn with the same axis, and in some it may happen that some data points lie outside the plot. The solid lines represent the linear fit of the cloud of points, and the dashed lines the 50\% percentile ones. Fig. 9(c) shows the slope of each linear fit of these clouds of points [solid lines in Fig. 9(a) and (b)] versus incidence angle (solid line), which indicate the sensitivity of the $T_{B}$ modulation due to wind speed, 


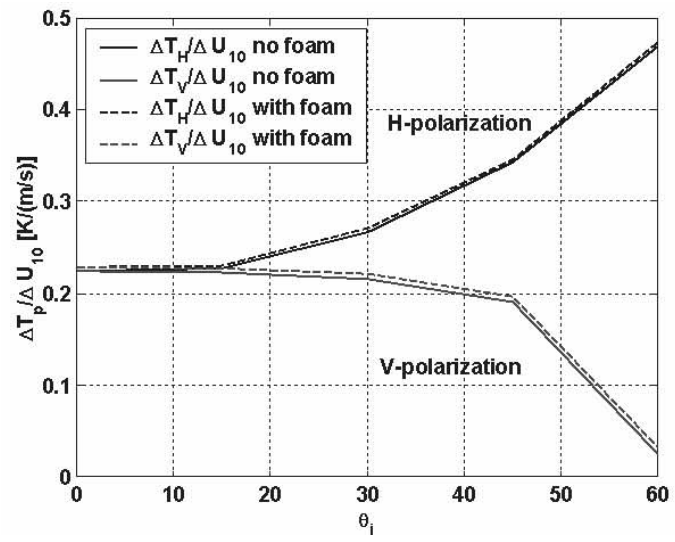

(a)

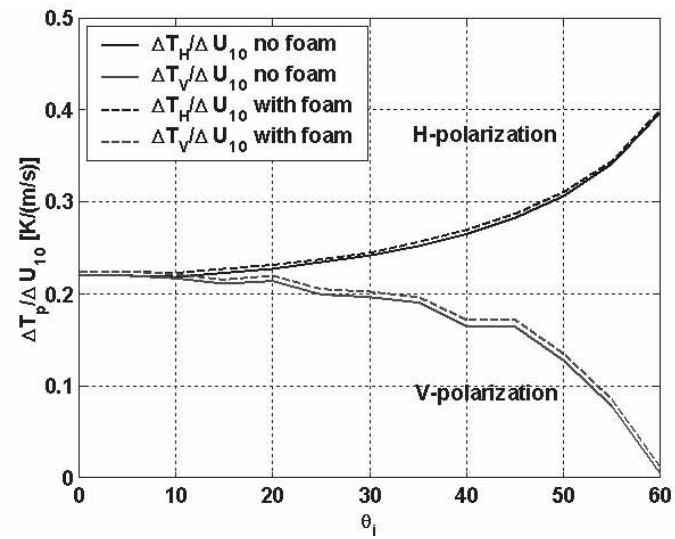

(b)

Fig. 8. Weighted average of the brightness temperatures sensitivities (H- and V-polarizations, (solid line) no foam, (dashed line) with WISE foam emissivity) to wind speed by the WISE 2001 wind speed histogram $\left(U_{10}>2 \mathrm{~m} / \mathrm{s}\right)$ for (a) the Durden and Vesecky spectrum times two and (b) the Elfouhaily et al. spectrum times two.

(a)
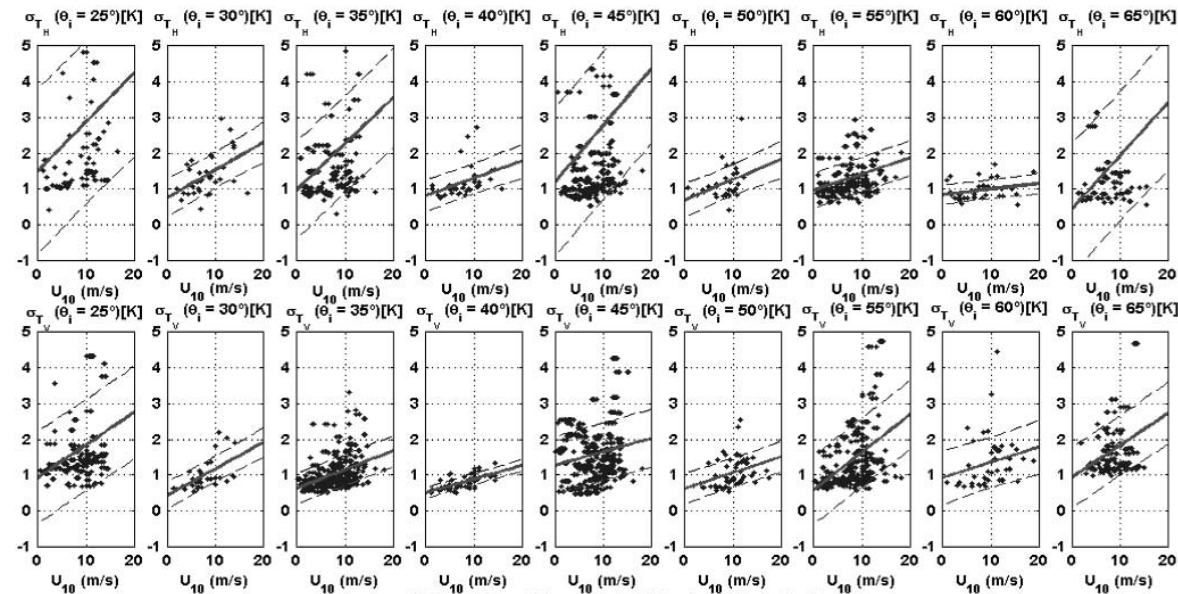

$U_{10}^{(m / s)}($ circles $)$

Sensitivity to $\mathrm{U}_{10}: \mathrm{H}$-(squares) \& V-polarization (circles)

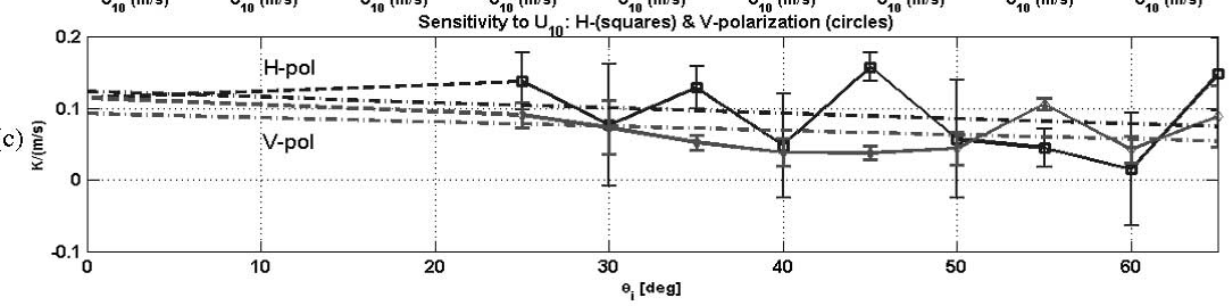

Fig. 9. Derivation of the brightness temperature standard deviation sensitivity to wind speed. (a) H-polarization and (b) V-polarization scatter plots, (solid line) linear fit and (dashed lines) percentile $50 \%$ as a function of wind speed for incidence angles from $25^{\circ}$ to $65^{\circ}$. (c) Derived $\sigma_{\mathrm{TB}}$ sensitivity to wind speed as a function of (solid line) polarization and incidence angle, associated $\pm 1 \sigma$ error bars, and (dashed lines) linear fit. All data points used.

with the associated $\pm 1 \sigma$-error bars computed from the $50 \%$ percentile values [dashed lines in Fig. 9(a) and (b)]. The dashed lines in Fig. 9(c) show the linear interpolation of the sensitivity of the $T_{B}$ modulation to wind speed, which is approximately $0.10-0.15 \mathrm{~K} /(\mathrm{m} / \mathrm{s})$ at both polarizations, which is nearly independent of the incidence angle. The lower sensitivity values at $\theta_{i}=30^{\circ}, 40^{\circ}$, $50^{\circ}$, and $60^{\circ}$ (measurements pointing to the northeast) are attributed to the destructive interference of the waves coming from the north or northeast (dominant wind direction) that were reflected on the platform, a phenomenon that is also responsible of the lower sea foam coverage as a function of wind speed measured during WISE 2000 [16]. This point has been checked reanalyzing the radiometric data for those measurements pointing only to the north and northeast. In this case, the sensitivity of the $T_{B}$ modulation to wind speed is very small, in the range $0-0.08 \mathrm{~K} /(\mathrm{m} / \mathrm{s})$ at both polarizations, except at $25^{\circ}$ incidence angle, and at $65^{\circ}$ where this interference effect was not noticeable.

A more detailed analysis reveals that the instantaneous brightness temperatures not only contains information on the wind speed, but on the whole sea state and the presence of foam. For example, Fig. 10(a) shows a buoy-measured sea surface elevation and the derived sea surface slope spectra. Fig. 10(b) shows the Fourier transform of the instantaneous brightness temperatures, which follow the sea surface slope spectra, with peaks located in the same positions (wind-driven spectrum + swell) [24]. 


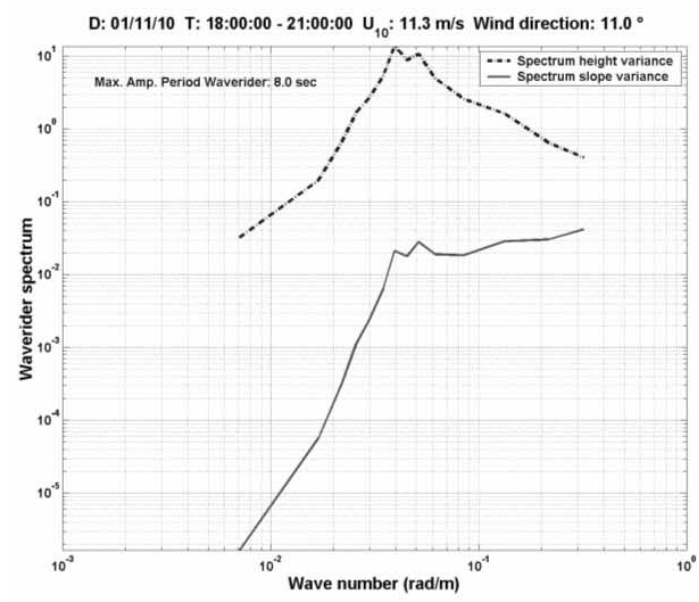

(a)

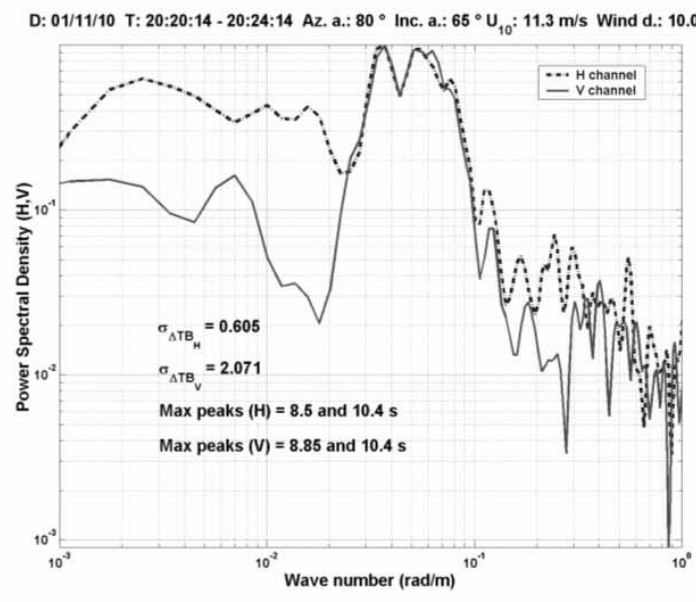

(b)

Fig. 10. (a) (Solid line) Sample sea surface slope spectrum derived from (dashed line) Waverider buoy-measured sea surface height spectrum, and (b) corresponding instantaneous brightness temperature power spectra [(solid line curve) V-polarization and (dashed line) H-polarization]. Brightness temperature spectra derived from Fourier transformation of the instantaneous brightness temperature samples and transformation of frequencies to wave numbers using the deep-waters dispersion relationship.

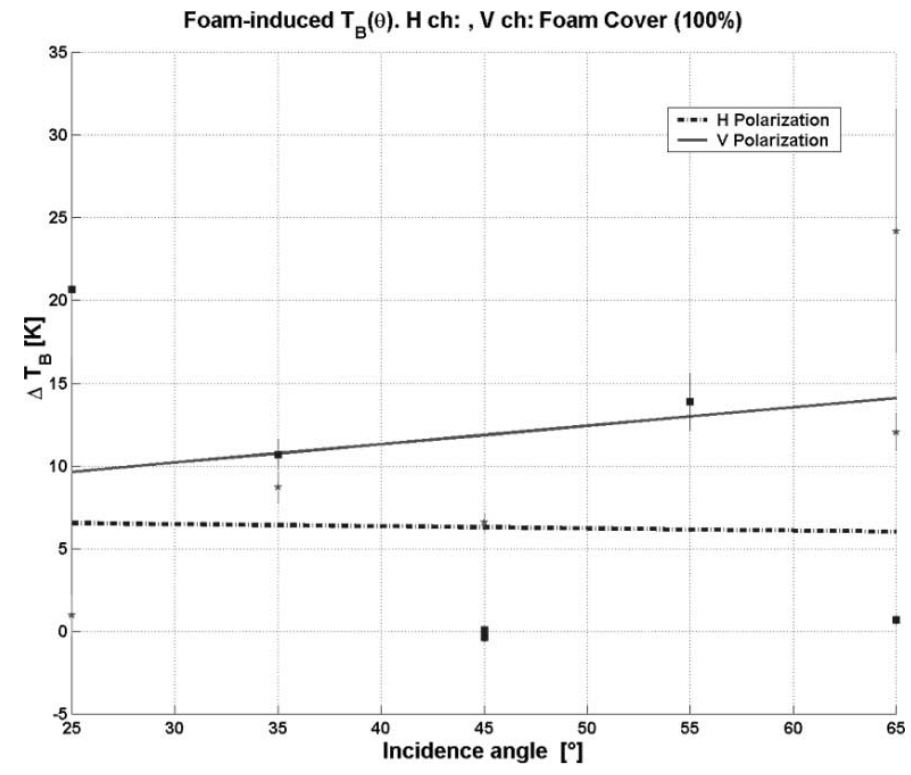

Fig. 11. Brightness temperature increase versus incidence angle and polarization for a $100 \%$ foam-covered sea surface [24].

A correlation has also been found between the peaks in $T_{B}(t)$ and the instantaneous foam coverage time series. It is estimated that, as compared to a foam-free sea spot, the presence of a $100 \%$ foam-covered spot will produce a brightness temperature increase from $10-15 \mathrm{~K}$ at $\mathrm{V}$-polarization, and nearly constant and about $6 \mathrm{~K}$ at $\mathrm{H}$-polarization, in the whole range of incidence angles from $25^{\circ}$ to $65^{\circ}$ (see Fig. 11 and [24]). These values, together with the fractional foam coverage estimated as a function of wind speed can be used to estimate the global impact on the brightness temperatures. However, it should be noted that this relationship depends on many other parameters rather than wind speed [24]-[26], such as the atmospheric instability, the salinity, the fetch, etc., and the variations for the same wind speed value can be significant. During WISE 2000 and 2001, approximately 20000 and 63000 different photograms were analyzed. The fractional surface foam coverage (all types of foam included) was found to be $F_{\mathrm{WISE} 2000}\left(U_{10}\right)=2.32 .10^{-6} \cdot U_{10}^{3.4988}$ and $F_{\mathrm{WISE} 2001}\left(U_{10}\right)=0.43 .10^{-6} \cdot U_{10}^{3.6824}$, respectively. Note that the wind exponent is approximately the same in both field experiments $(\sim 3.5)$. Howerver, its impact of the brightness temperatures $\left(\Delta T_{B}^{100 \% \text { foam }} \cdot F\left(U_{10}\right)\right)$ is small, and only above $15 \mathrm{~m} / \mathrm{s}$ is it larger than $\sim 0.1 \mathrm{~K}$.

- Brightness temperature sensitivity to the significant wave height: To derive the brightness temperature sensitivity to the significant wave height ${ }^{6}$ (SWH), a brightness temperature deviation from the flat surface model is computed from

$$
\begin{array}{r}
T_{B, p}\left(\theta_{i}, \mathrm{SST}, \mathrm{SSS}, \mathrm{SWH}\right)=T_{B \text { Fresnel, } p}\left(\theta_{i}, \mathrm{SST}, \mathrm{SSS}\right) \\
+\Delta T_{B \text { SWH }, p}\left(\theta_{i}, \mathrm{SWH}\right)
\end{array}
$$

where $T_{B \text { Fresnel, } p}\left(\theta_{i}, \mathrm{SST}, \mathrm{SSS}\right)$ is defined in (2) and corresponds to the emissivity computed from the Fresnel field reflection coefficient at $p$-polarization. Fig. 12 shows the plots of the brightness temperatures deviation due to the significant wave height $\left(\Delta T_{B} \mathrm{SWH}, \rho\right)$ at horizontal (upper row) and vertical (central row) polarizations versus the $\mathrm{SWH}$, for incidence angles from $25^{\circ}$ to $65^{\circ}$, in $5^{\circ}$ steps. The solid line in each plot represents the regression line and the dashed ones the $50 \%$ percentile ones. The plot at the lower part of Fig. 12 shows the slope of each regression line as a function of the incidence angle, which corresponds to the average sensitivity to SWH in Kelvins per meter at $\mathrm{H}$ - and V-polarizations. A linear fit of these

${ }^{6}$ Significant wave height as used in (8) is the average of the highest third of the waves. 
(a)
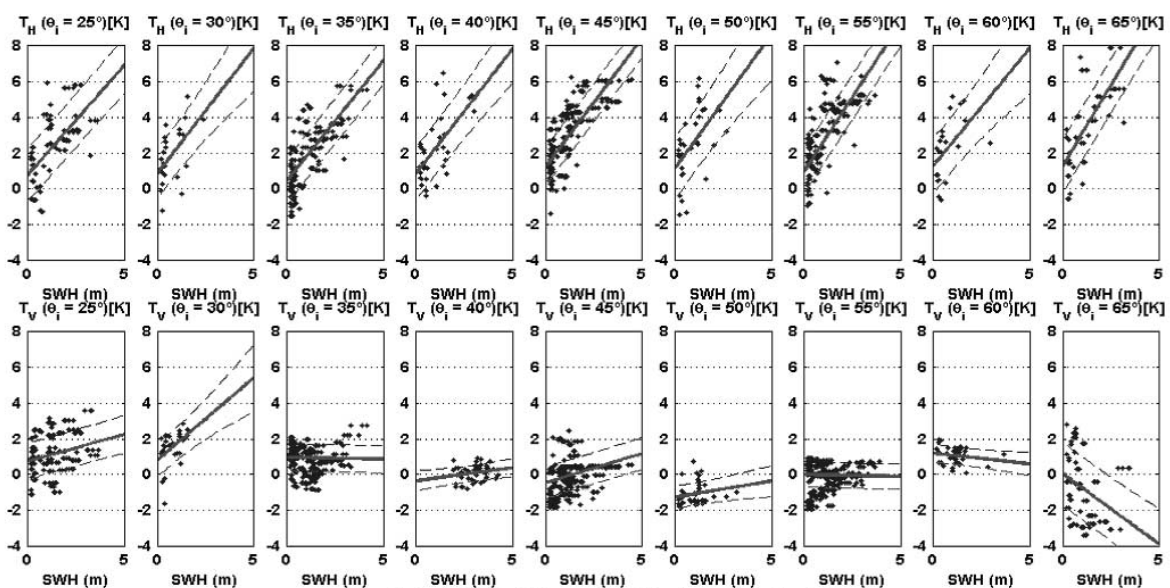

Sensitivity to SWH: H-(squares) \& V-polarization (circles)

(c)

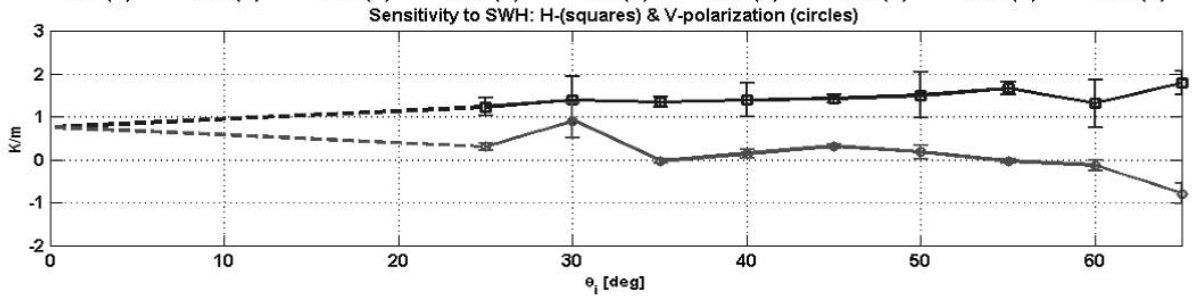

Fig. 12. Derivation of the brightness temperature sensitivity to SWH (a) $\Delta T_{B \mathrm{SWH}, h}$ and (b) $\Delta T_{B \mathrm{SWH}, v}$ scatter plots, (solid line) linear fit and (dashed lines) percentile $50 \%$ as a function of the SWH for incidence angles from $25^{\circ}$ to $65^{\circ}$. (c) Derived SWH sensitivity as a function of (solid line) polarization and incidence angle associated $\pm 1 \sigma$ error bars, and (dashed lines) linear fit.

values leads to the following relationships and correlation coefficients:

$$
\begin{array}{ll}
\Delta T_{h} \approx 1.09\left(1+\frac{\theta}{142}\right) \mathrm{SWH}, & r_{h}=0.88 \\
\Delta T_{v} \approx 0.92\left(1-\frac{\theta}{51^{\circ}}\right) \mathrm{SWH}, & r_{v}=0.78 .
\end{array}
$$

The extrapolated sensitivity at nadir is then

$$
\frac{\Delta T_{B, p}\left(\theta_{i}=0^{\circ}\right)}{\Delta \mathrm{SWH}} \approx 1 \mathrm{~K} / \mathrm{m} \text {. }
$$

Equation (9) has also successfully been used in sea surface salinity retrieval algorithms and has proved to be more robust than (4), when satellite-derived wind speed is used [27] (Section IV).

- Brightness temperature azimuthal angle signature: We must distinguish two different regimes: low to moderate and strong wind conditions. The first one was dominant during all WISE 2000 and part of WISE 2001. In this regime, the azimuthal signature is very weak-almost inexistent-and difficult to identify. In the strong-wind conditions that happened during the first half of November 2001 , the brightness temperature azimuthal signature is quite clear, reaching a few Kelvin.

Camps et al. [16, Fig. 11] shows typical measurements (5-min averaging) of azimuth scans at horizontal (left) and vertical (right) polarizations for three different low to moderate wind speeds and incidence angles: (a) and (b) $\theta_{i}=25^{\circ}$, $U_{10}=2.7 \mathrm{~m} / \mathrm{s}$, (c) and (d) $\theta_{i}=45^{\circ}, U_{10}=2.8 \mathrm{~m} / \mathrm{s}$, and (e) and (f) $\theta_{i}=35^{\circ}, U_{10}=10.9 \mathrm{~m} / \mathrm{s}$. Even though there are very few data points covering about one third of a full $360^{\circ}$ scan, a small $0.1-0.2 \mathrm{~K}$ difference is suspected. At L-band,
TABLE III

Computed $T_{v} / T_{h}$ Peak-to-PeaK Azimuthal Modulation of the BRIGHTNESS TEMPERATURE FOR DIFFERENT WIND SPEEDS USING the SSA Method and ElFOUhaily et al.'s SEA SPECTRUM. OTHER PARAMETERS: SSS $=38 \mathrm{psu}, \mathrm{SST}=20^{\circ} \mathrm{C}$

\begin{tabular}{cccccc}
\hline$\theta_{i}$ & 0 & 25 & 35 & 45 & 55 \\
\hline$U_{10}=5 \mathrm{~m} / \mathrm{s}$ & $0.46 / 0.46$ & $0.48 / 0.53$ & $0.44 / 0.60$ & $0.39 / 0.63$ & $0.28 / 0.58$ \\
$U_{10}=10 \mathrm{~m} / \mathrm{s}$ & $0.48 / 0.48$ & $0.53 / 0.57$ & $0.49 / 0.62$ & $0.41 / 0.61$ & $0.29 / 0.47$ \\
$U_{10}=15 \mathrm{~m} / \mathrm{s}$ & $0.63 / 0.63$ & $0.66 / 0.70$ & $0.61 / 0.73$ & $0.53 / 0.69$ & $0.39 / 0.44$ \\
$U_{10}=20 \mathrm{~m} / \mathrm{s}$ & $0.78 / 0.78$ & $0.85 / 0.87$ & $0.79 / 0.90$ & $0.68 / 0.81$ & $0.52 / 0.46$ \\
\hline
\end{tabular}

the azimuthal signature computed with two-scale methods strongly depends on the spectrum spreading function [5], [20]. Table III summarizes the peak-to-peak variations at different wind speeds and incidence angles computed with the SSA method and Elfouhaily et al.'s sea spectrum.

On November 10 and 15, 2001, the two strongest storms were recorded on the platform. Meteorological and oceanographic conditions were similar in both storms, except for the wind direction: northwest on November 10 and northeast on November 15 . Only measurements corresponding to November 10 are available, since the radiometer control was lost on November 15, around 11 A.M.

Fig. 13(a) shows a time series of consecutive measurements (one sample per second) at vertical and horizontal polarizations for various azimuth angles at $45^{\circ}$ incidence angle, while the storm was becoming more and more intense. Average wind speed at $10 \mathrm{~m}$ is just $11.0 \mathrm{~m} / \mathrm{s}$, but the significant wave height corresponds to the highest peak in Fig. 5. The large standard deviation of the measurements-several Kelvin-is due to the brightness temperature modulation produced by the waves [24], and the highest brightness temperature peaks correspond to wave 

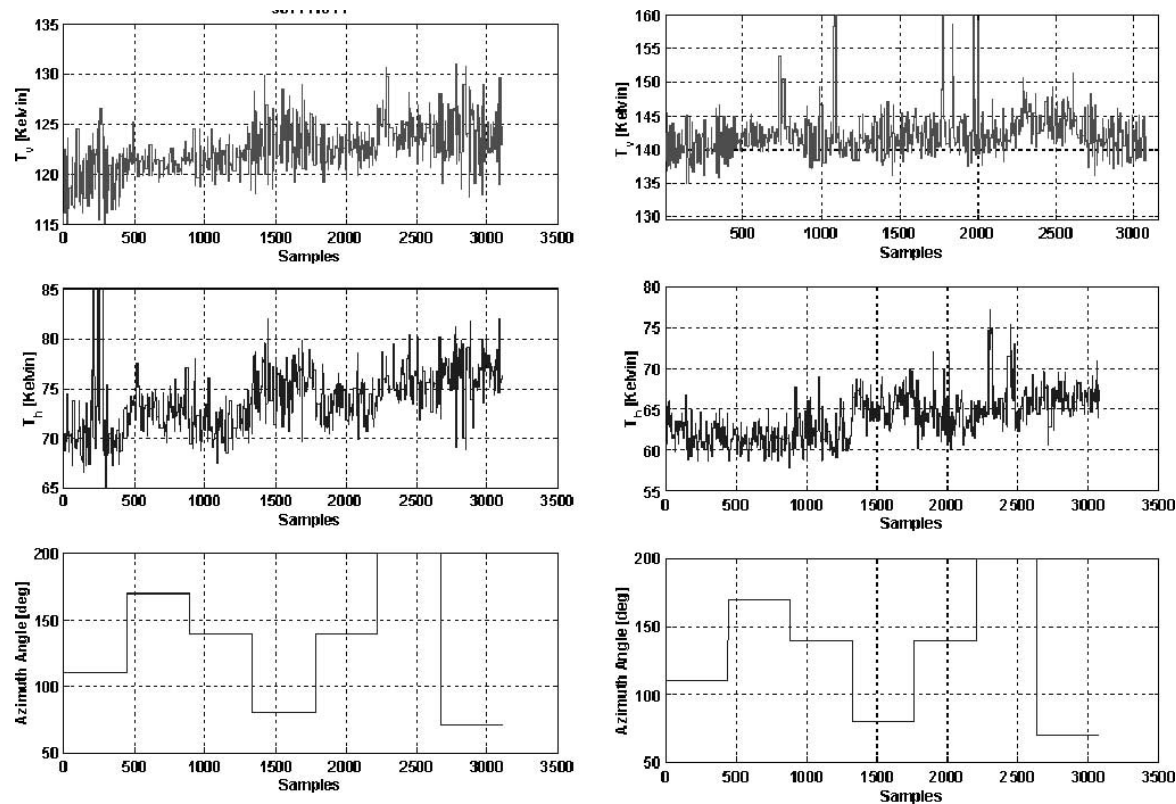

(a)

(c)
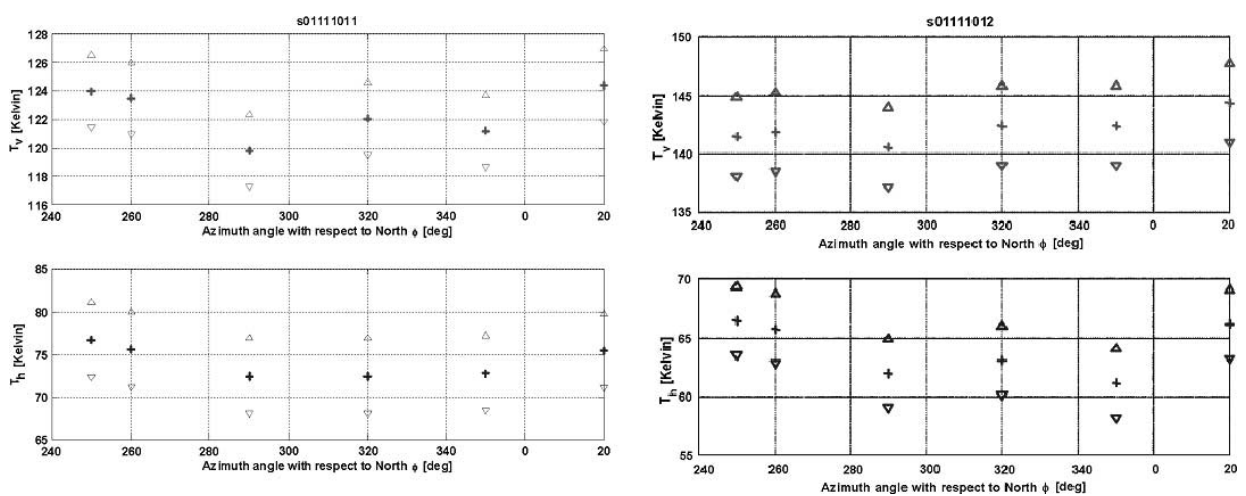

(b)

(d)

Fig. 13. (a) Series of samples acquired during an azimuth scan at $45^{\circ}$ incidence angle. November $10,2001,19 \mathrm{~h} . U_{10}=11.0 \mathrm{~m} / \mathrm{s}$, (b) Average values and average values plus minus one standard deviation for each azimuth angle (with respect to the north) corresponding to (a). (c) Series of samples acquired during an azimuth scan at $55^{\circ}$ incidence angle. November 10, 2001, $20 \mathrm{~h}, U_{10}=12.4 \mathrm{~m} / \mathrm{s}$. (d) Average values and average values plus minus one standard deviation for each azimuth angle corresponding to Fig. 13(c).

breaking events, when foam is produced. Note also the correlation between the values averaged at each azimuth angle and the azimuth angle. The linear trend observed on $T_{B}$ is probably due to the fact that the storm was becoming more and more intense. Fig. 13(b) shows the average value (crosses) and the average value plus minus one standard deviation (triangles) of the values shown in Fig. 13(a), plotted versus the azimuth angle with respect to the south. Fig. 13(c) and (d) shows another azimuth scan at $55^{\circ}$ incidence angle. As in the former case, the $T_{v}$ and $T_{h}$ signals have a standard deviation larger than instruments radiometric sensitivity, but the average values are correlated to the azimuth angle. As can be appreciated in Fig. 13(d), the amplitude of the azimuthal signal is smaller in $T_{v}$ than in the former case, since the sensitivity to wind speed vanishes around $55^{\circ}$ incidence angle.

It should be pointed out that the measured amplitude modulations are too large as compared to model predictions (Table III), even if Elfouhaily et al.'s sea spectrum were multiplied by two. Further research is needed to understand its origin, peakier waves due to nonfully developed sea, wave foam emission and asymmetric foam distribution, etc.

\section{Application to Multiangular sea SURFACE SALINITY RETRIEVAL}

The empirical models developed in the Section III are now applied to the performance study of sea surface salinity retrieval algorithms, including the impact of errors in the ancillary data (wind speed and sea surface temperature). The algorithm used here to retrieve the salinity from brightness temperature data is a recurrent least squares fit called Levenberg-Marquardt [28]. It has been chosen for its easy implementation and computational efficiency. The brightness temperatures are computed setting an initial guess for sea salinity, temperature, and wind speed (or significant wave height) into the direct emissivity model [(1) and (9)] using the Klein and Swift's dielectric constant model [13]. This value is compared with the brightness temperatures measured by the radiometer, and then an increment $\Delta \mathrm{SSS}$ is added to the initial salinity. An increment can also be added to the wind speed, which is found to be a critical parameter. It happens that the actual wind speed is not representative of the actual sea state, and an "effective" wind speed can be found 


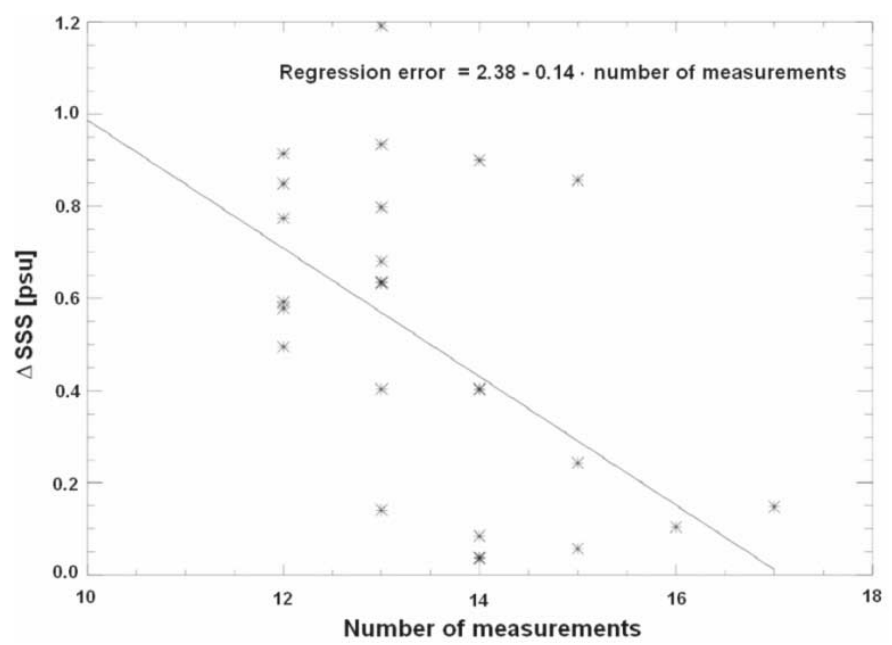

Fig. 14. SSS retrieval errors as function of the number of measurements (incidence angles + polarizations).

by the SSS retrieval algorithm that best fits the measurements. This recursive method is stopped when the difference between the measured and the computed $T_{B}$ is smaller than a specified threshold. Fig. 14 shows the retrieval error in 25 different cases when using different number of available measurements (incidence angles and polarizations). It is, however, surprising the fast decrease of $\Delta \mathrm{SSS}$ with the number of available measurements. Wind speed and sea surface temperature data have been taken from buoy measurements. Only scans with 12 or more data points (different incidence angles and polarizations) have been used. It is clear that the SSS retrieval quality increases with the number of measurements.

In the SMOS case, the salinity retrieval problem requires the knowledge of other variables (wind speed or significant wave height and sea surface temperature) as close as possible both in time and space to the radiometric measurements. Errors in these parameters translate into sea surface salinity errors. During WISE field experiments, QUIKSCAT and AVHRR satellite measurements were acquired, as well as data from the ARPEGE numerical weather model.

QUIKSCAT Wind speed data: In this study, wind speed products of the NASA satellite-borne QUIKSCAT scatterometer with $2-\mathrm{m} / \mathrm{s}$ accuracy and $25-\mathrm{km}$ spatial resolution were used. They are colocated with the platform using a radius of $0.27^{\circ}$ latitude and $0.37^{\circ}$ longitude. During WISE 2000 and 2001, 196 and 74 datasets were available, respectively. Since the scatterometer cannot measure closer than $50 \mathrm{~km}$ from the coast, there were no measurements coincident with the platform: they were mostly southeast, the closest $3 \mathrm{~km}$ away from the platform, the farther $40 \mathrm{~km}$ away. These wind speed data were averaged for each satellite pass, and the resulting averages were compared with 1-h average of the in situ measurements. During WISE 2000, when compared to the oil rig meteorological station measurements brought at $10-\mathrm{m}$ height in neutral atmosphere, the average difference is $0.44 \mathrm{~m} / \mathrm{s}$, with $2.8-\mathrm{m} / \mathrm{s}$ standard deviation of the difference. During WISE 2001, there were not enough data to make the comparison with a reasonable statistical significance.
AVHRR SST data: LAC images of the AVHRR instrument at a spatial resolution of $1.1 \mathrm{~km}$ were recorded and processed by the Service d'Archivage et de Traitement Meteorologique des Observations Spatiales, Méteo-France/CNRS (SATMOS) data center. Many images were cloudy. AVHRR SST estimates have an uncertainty up to $0.1{ }^{\circ} \mathrm{C}$ in clear sky conditions, and $0.3{ }^{\circ} \mathrm{C}$ otherwise. During WISE 2000, the Ebro fresh and usually colder plume was observed and even reached the Casablanca oil rig, but not during WISE 2001.

ARPEGE wind speed data: Surface wind speeds from the analyzed surface fields of ARPEGE, Méteo-France's meteorological model, have been colocated with the Casablanca Platform. The resolution of the model is 25 $\mathrm{km}, 6 \mathrm{~h}$, and the uncertainty is $2.15 \mathrm{~m} / \mathrm{s}$. The colocation radius is the same as for QUIKSCAT, i.e., $0.27^{\circ}$ latitude and $0.37^{\circ}$ longitude, resulting in nine grid points colocated for each field. The data are from October 1 to November $30,2001$.

Fig. 15(a) shows the errors on the retrieved salinity for four different sources of wind speed: 1) wind measured in situ by the buoy anemometer $\left(\Delta \mathrm{SSS}=0.52 \mathrm{psu}, \sigma_{\Delta \mathrm{SSS}}=0.12 \mathrm{psu}\right)$; 2) wind from QUIKSCAT satellite $(\Delta \mathrm{SSS}=0.77 \mathrm{psu}$, $\left.\sigma_{\Delta \mathrm{SSS}}=0.72 \mathrm{psu}\right){ }^{7}$ 3) wind from ARPEGE model ( $\Delta \mathrm{SSS}=0.57 \mathrm{psu}, \sigma_{\Delta \mathrm{SSS}}=0.19 \mathrm{psu}$ ); and 4) leaving the wind as an unknown parameter within the range of the measured value plus or minus the measurement error, and allowing the retrieval algorithm to derive the values of salinity and an "effective" wind speed $\left(\Delta \mathrm{SSS}=0.59 \mathrm{psu}, \sigma_{\Delta \mathrm{SSS}}=0.12 \mathrm{psu}\right.$; and $\Delta \mathrm{WS}=1.15 \mathrm{~m} / \mathrm{s}, \sigma_{\Delta W S}=0.54 \mathrm{~m} / \mathrm{s}$ ).

It can be appreciated that when the measured wind has large errors, the retrieved salinity values also have large errors ( $2 \mathrm{psu}$ ). In this case, the option of leaving the wind as a free parameter seems to improve significantly the retrieved salinity as compared to case of having the wind speed value fixed. Fig. 15(b) shows the retrieved salinity error and error bar when using the buoy-measured SST plus $0.3^{\circ} \mathrm{C}$ random error to simulate AVHRR-derived SST. ${ }^{8}$ As expected from the low sensitivity to sea surface temperature, in these cases there is no significant difference among them.

Finally, Fig. 16 plots the retrieved salinity error as a function of the wind speed and the significant wave height. It can be appreciated that the salinity retrieval error increases with both wind speed and significant wave height. This effect is not fully understood, but may be probably due to limited fetch and foam effects not directly included in the models. ${ }^{9}$ Since the foam coverage increases with wind speed, and it increases the brightness temperature, the retrieval algorithm tends to decrease the retrieved salinity to compensate for the brightness temperature increment. The same happens when considering the significant wave height, which is strongly correlated to wind speed, except in a few situations of swell. Then mean salinity error

\footnotetext{
${ }^{7}$ In datasets 10-12, QuikSCAT wind speed is much higher than the one observed by the buoys.

${ }^{8}$ Most days were cloudy, and AVHRR SST was not available.

${ }^{9}$ Note that in the derivation of (1) and (9), the larger number of data points corresponds to wind speeds smaller than $10 \mathrm{~m} / \mathrm{s}$, where the foam fraction coverage is negligible.
} 


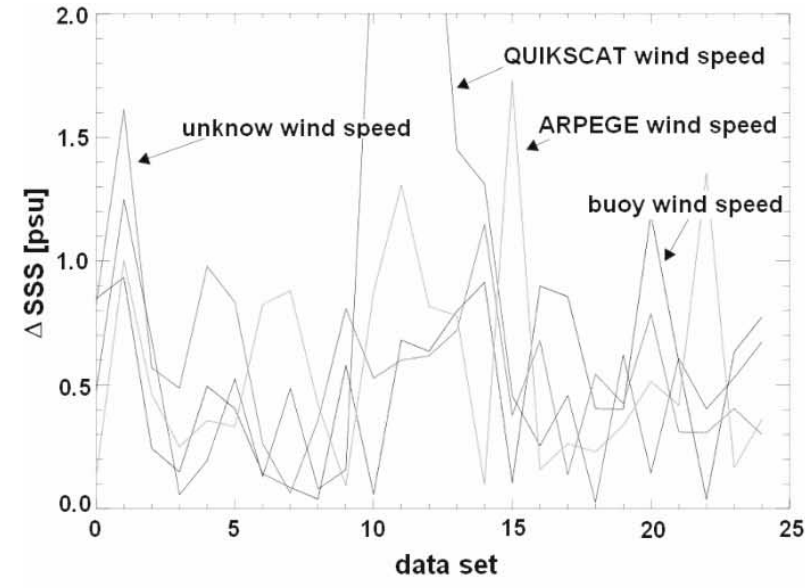

(a)

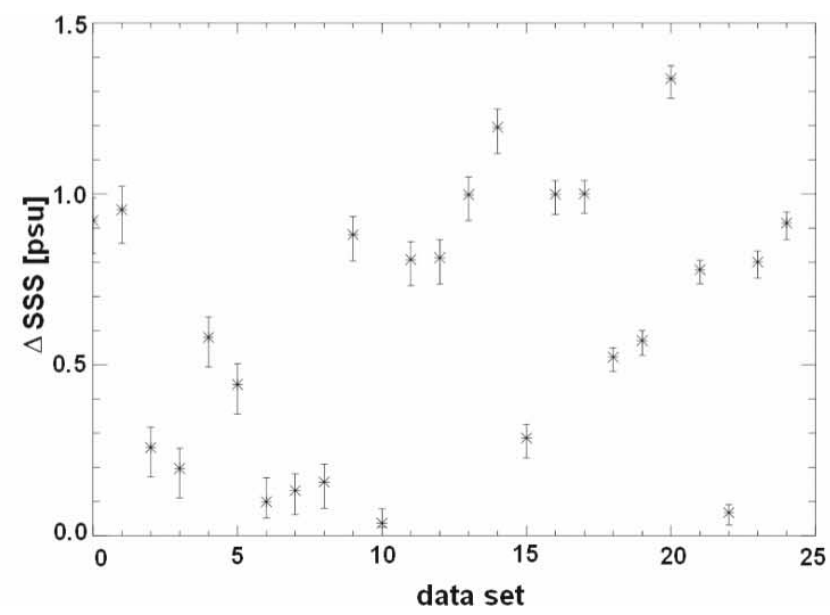

(b)

Fig. 15. Sea surface salinity retrieval error (absolute value) using (a) four different sources of wind speed: measured by the buoy, measured by QUIKSCAT, ARPEGE model, and left as a free parameter (with constraints) in the retrieval algorithm and (b) buoy-measured STT plus $0.3{ }^{\circ} \mathrm{C}$ random error to simulated AVHRR-derived SST.

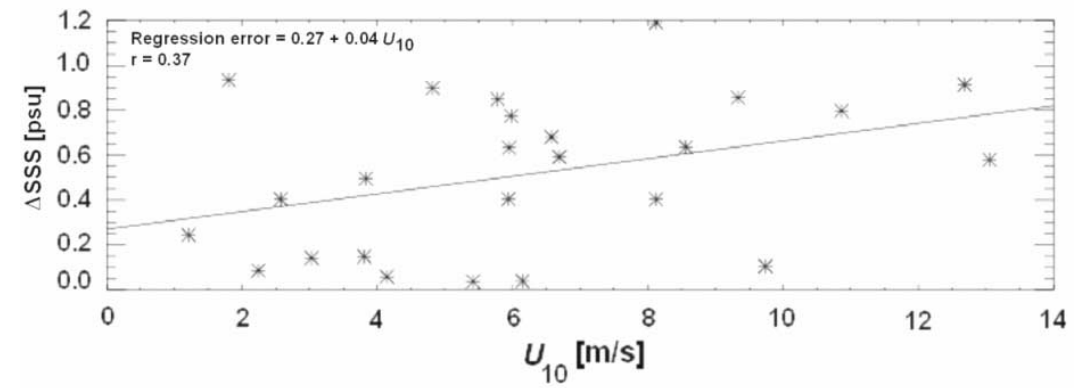

(a)

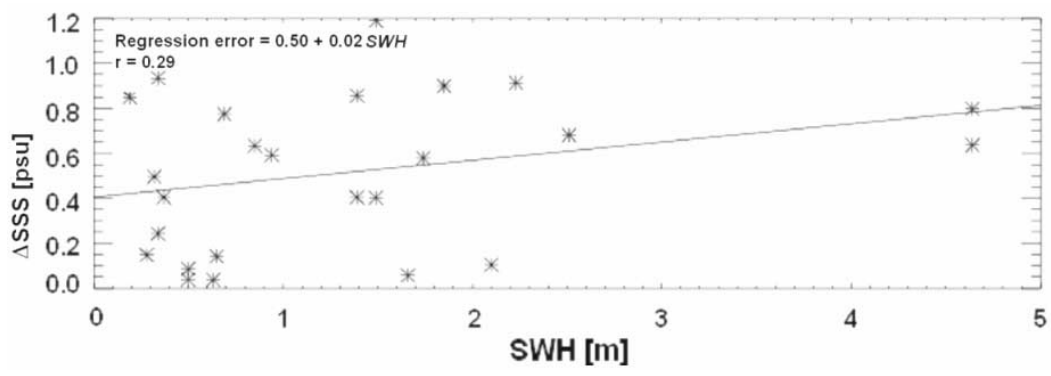

(b)

Fig. 16. Sea surface salinity retrieval error dependence with (a) wind speed and (b) significant wave height.

and standard deviation when using wind speed and significant wave height are $\Delta \mathrm{SSS}=0.52 \mathrm{psu}, \sigma_{\Delta \mathrm{SSS}}=0.12 \mathrm{psu}$, and $\Delta \mathrm{SSS}=0.84 \mathrm{psu}, \sigma_{\Delta \mathrm{SSS}}=0.35 \mathrm{psu}$, respectively. Despite the worse results of using the significant wave height information, further analyses are required to determine its potential advantage, since the significant wave height dependence is less variable than the wind speed, and that it includes other surface roughness effects not due to local winds.

\section{CONCLUSION}

The results of the L-band radiometric data acquisition and processing of WISE 2000 and 2001 field experiments have been presented. During WISE 2000, much data were corrupted by
RFI, and derived brightness temperatures sensitivities to wind speed were in agreement with previous [1] measurements, but the associated error bounds were large. In WISE 2001, the situation improved dramatically, mainly because the 2000 drilling activities in the platform had already finished. The processing of the data reveals the following.

- A sensitivity to wind speed extrapolated at nadir of $\sim 0.23 \mathrm{~K} /(\mathrm{m} / \mathrm{s})$, or a little bit higher $\sim 0.25 \mathrm{~K} /(\mathrm{m} / \mathrm{s})$ when the atmospheric instability or only the measurements corresponding to $U_{10}>2 \mathrm{~m} / \mathrm{s}$ are accounted for. This sensitivity increases at $\mathrm{H}$-polarization up to $\sim 0.5 \mathrm{~K} /(\mathrm{m} / \mathrm{s})$ at $65^{\circ}$, and decreases at V-polarization down to $\sim-0.2 \mathrm{~K} /(\mathrm{m} / \mathrm{s})$ at $65^{\circ}$, with a zero-crossing around $55^{\circ}$ to $60^{\circ}$. These results are in agreement 
with the SSA method using Durden and Vesecky's and Elfouhaily et al.'s sea spectra times two. It is very likely that the computed wind speed sensitivities below $2 \mathrm{~m} / \mathrm{s}$ are erroneous.

- A modulation of the instantaneous brightness temperatures due to wave slopes (and also foam), which makes the standard deviation of this modulation increase with wind speed at a rate of $\sim 0.1-0.15 \mathrm{~K} /(\mathrm{m} / \mathrm{s})$, depending on polarization, and very weakly on incidence angle.

- A sensitivity to significant wave height extrapolated to nadir of $\sim 1 \mathrm{~K} / \mathrm{m}$, increasing at $\mathrm{H}$-polarization up to $\sim$ $1.5 \mathrm{~K} / \mathrm{m}$ at $65^{\circ}$, and decreasing at $\mathrm{V}$-polarization down to $-0.5 \mathrm{~K} / \mathrm{m}$ at $65^{\circ}$.

- A small azimuthal modulation $\sim 0.2-0.3 \mathrm{~K}$ for low to moderate wind speeds, in reasonable agreement with numerical models. However, a large peak-to-peak modulation of 4-5 $\mathrm{K}$ was measured during a strong storm recorded on November 10, 2001.

The brightness temperature sensitivity to wind speed and significant wave height has been obtained and compared satisfactorily to numerical models. Multiangular brightness temperature data has been successfully used to retrieve sea surface salinity with a 0.52-psu bias and 0.12-psu rms error using the derived wind speed sensitivities. This work is a step forward to the development of operational sea salinity retrieval algorithms from space for the SMOS mission.

\section{ACKNOWLEDGMENT}

The WISE 2000 and 2001 field experiments were sponsored by ESA. The French moorings were supported by the CNES, and the buoy data handling by Méteo-France, with special thanks to P. Blouch. The radiometric data processing, field experiment logistics, and salinity retrieval studies were sponsored by the Spanish grants MCYT TIC 2002-04451-C02-01 and PNE 009/2001-C-02. Last, but not least, the authors very much appreciate all the cooperation and help provided by the personnel of Repsol Investigaciones Petrolíferas-Base Tarragona-Plataforma Casablanca for the organization of the field experiment, without whose help WISE could not have been performed. The authors are very grateful to four anonymous reviewers whose detailed and careful review has helped to increase the clarity of this work.

\section{REFERENCES}

[1] C. T. Swift and R. E. McIntosh, "Considerations fro microwave remote sensing of ocena-surface salinity," IEEE Trans. Geosci. Electron., vol. GE-21, no. 4, pp. 480-491, Oct. 1983.

[2] P. Silvestrin, M. Berger, Y. Kerr, and J. Font, "ESA's second Earth Explorer Opportunity Mission: The Soil Moisture and Ocean Salinity mission-SMOS," IEEE Geosci. Remote Sensing Newslett., no. 118, pp. 11-14, Mar. 2001.

[3] M. Martín-Neira and J. M. Goutoule, "A two-dimensional aperture-synthesis radiometer for soil moisture and ocean salinity observations," ESA Bull., no. 92, pp. 95-104, Nov. 1997.

[4] G. S. E. Lagerloef, "Report of the 3rd Workshop, Salinity Sea Ice Working Group," Earth and Space Res., Seattle, WA, http://www.esr.org/ssiwg3/SSIWG_3.html, 2000.

[5] J. Johannessen et al., "Scientific requirements and impact of space observations of ocean salinity for modeling and climate studies,", ESA contract 14273/00/NL/DC, 2002.
[6] A. Camps, J. Font, J. Etcheto, V. Caselles, and A. Weill, "WISE 2000 and 2001: Campaign description and executive summary," in Proc. EuroSTARSS, WISE, LOSAC Workshop, 2003, ESA SP-525, pp. 17-26.

[7] R. Villarino, L. Enrique, A. Camps, I. Corbella, and S. Blanch, "Design, implementation and test of the UPC L-band automatic radiometer," in Proc. URSI Commission-F 2002 Open Symp., Garmisch-Partenkirchen, Germany, Feb. 2002.

[8] W. Reich, "A radio continuum survey of the northern sky at 1420 MHz_Part I," Astron. Astrophys. Suppl. Ser, vol. 48, pp. 219-297, 1982

[9] P. Reich and W. Reich, "A radio continuum survey of the northern sky at $1420 \mathrm{MHZ}-P a r t$ II," Astron. Astrophys. Suppl. Ser., vol. 63, pp. 205-292, 1986.

[10] H. J. Liebe, "MPM-An atmospheric millimeter wave propagation model," Int. J. Inf. Millim. Waves, vol. 10, no. 6, pp. 631-650, 1989.

[11] A. Camps, F. Torres, I. Corbella, J. Bará, and X. Soler, "Calibration and experimental results of a two-dimensional interferometric radiometer laboratory prototype," Radio Sci., vol. 32, no. 5, pp. 1821-1832, Sept.-Oct. 1997.

[12] A. Camps, I. Corbella, M. Vall-llossera, N. Duffo, F. Torres, R. Villarino, L. Enrique, J. Miranda, F. Julbé, J. Font, A. Julià, C. Gabarro', J. Etchetto, J. Boutin, A. Weill, V. Caselles, E. Rubio, P. Wursteisen, M. Berger, and M. Martín-Neira, "L-band sea surface emissivity: Preliminary results of the WISE-2000 campaign and its application to salinity retrieval in the SMOS mission," Radio Sci., vol. 38, no. 4, p. 8071.

[13] L. A. Kelin and C. T. Swift, "An improved model for the dielectric constant of sea water at microwave frequencies," IEEE J. Oceanic Eng., vol. OE-2, no. 1, pp. 104-111, 1977

[14] W. Ellison, A. Balana, G. Delbos, K. Lamkaouchi, L. Eymard, C. Guillou, and C. Prigent, "New permittivity measurements of sea water," Radio Sci., vol. 33, no. 3, pp. 639-648, May-June 1998.

[15] S. Blanch and A. Aguasca, "Sea water dielectric permittivity models: Review and impact on the brightness temperature at L-band," in Proc. EuroSTARSS, WISE, LOSAC Workshop, 2003, ESA SP-525, pp. 137-142.

[16] A. Camps, J. Font, J. Etcheto, V. Caselles, A. Weill, I. Corbella, M. Vall-llossera, N. Duffo, F. Torres, R. Villarino, L. Enrique, A. Julià, C. Gabarró, J. Boutin, E. Rubio, S. C. Reising, P. Wursteisen, M. Berger, and M. Martín-Neira, "Sea surface emissivity observations at L-band: First results of the wind and salinity experiment WISE 2000," IEEE Trans. Geosci. Remote Sensing, vol. 40, pp. 2117-2130, Oct. 2002.

[17] J. P. Hollinger, "Passive microwave measurements of sea surface roughness," IEEE Trans. Geosci. Electron., vol. GE-9, no. 3, pp. 165-169, 1971

[18] C. T. Swift, "Microwave radiometer measurements of the cape cod canal," Radio Sci., vol. 9, no. 7, pp. 641-653, 1974.

[19] A. Guissard, Atmospheric Instability Above the Ocean and Implications for Scatterometry, Dec. 2001, submitted for publication.

[20] M. Vall-llossera, J. Miranda, A. Camps, and R. Villarino, "Sea surface emissivity modeling at L-band: An inter-comparison study," in Proc. EuroSTARSS, WISE, LOSAC Workshop, 2003, ESA SP-525, pp. 143-154.

[21] S. L. Durden and J. F. Vesecky, "A physical radar cross-section model for a wind-driven sea with swell," IEEE J. Oceanic Eng., vol. OE-10, pp. 445-451, 1985.

[22] T. Elfouhaily, B. Chapron, K. Katsaros, and D. Vandermark, "A unified directional spectrum for long and short wind-driven waves," J. Geophys. Res., vol. 102, pp. 15 781-15 796, 1997.

[23] C. Cox and W. Munk, "Measurements of the roughness of the sea surface from photographs of the sun's glitter," J. Opt. Soc. Amer., vol. 44, pp. 838-850, 1954

[24] R. Villarino, A. Camps, M. Vall-llossera, J. Miranda, and J. Arenas, "Sea foam and sea state effects on the instantaneous brightness temperatures at L-band," in Proc. EuroSTARSS, WISE, LOSAC Workshop, 2003, ESA SP-525, pp. 95-104.

[25] E. Monahan and I. Muircheartaigh, "Whitecaps and the passive remote sensing of the ocean surface," Int. J. Remote Sens., vol. 7, no. 5, pp. 627-642, 1986.

[26] E. Monahan and M. Lu, "Acoustically relevant bubble asemblages and their dependence on meteorological parameters," IEEE J. Oceanic Eng., vol. 15 , Oct. 1990

[27] C. Gabarró, J. Font, A. Camps, and M. Vall-llossera, "Retrieved sea surface salinity and wind speed from L-band measurements for WISE and EUROSTARRS campaigns," in Proc. EuroSTARSS, WISE, LOSAC Workshop, 2003, ESA SP-525, pp. 163-172.

[28] W. Press, S. Teukolsky, W. Vetterling, and B. Flannery, Numerical Recipes in C. The Art of Scientific Computing, 2nd ed. Cambridge, U.K.: Cambridge Univ. Press, 1992. 


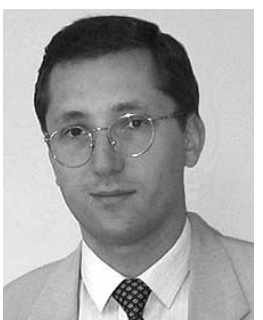

Adriano Camps (S'91-A'97-M'00-SM'02) was born in Barcelona, Spain, in 1969. He received the Telecommunications Engineering degree and the $\mathrm{Ph} . \mathrm{D}$. degree in telecommunications engineering in 1992 and 1996, respectively, both from the Polytechnic University of Catalonia (UPC), Barcelona, Spain.

From 1991 to 1992, he was with the ENS des Télécommunications de Bretagne, Bretagne, France, with an Erasmus Fellowship. In 1993, he joined the Electromagnetics and Photonics Engineering group, at the Department of Signal Theory and Communications, UPC, as an Assistant Professor, and since 1997 as an Associate Professor. In 1999, he was on sabbatical leave at the Microwave Remote Sensing Laboratory, University of Massachusetts, Amherst. His research interests are microwave remote sensing, with special emphasis in microwave radiometry by aperture synthesis techniques. He has performed numerous studies within the frame of European Space Agency SMOS Earth Explorer Mission. He is an Associate Editor of Radio Science.

Dr. Camps received the second national award of university studies in 1993, the INDRA award of the Spanish Association of Telecommunication Engineering to the best Ph.D. in 1997, the extraordinary Ph.D. award at the Universitat Politècnica de Catalunya in 1999, the First Duran Farell Award and the Ciudad de Barcelona Award, in 2000 and 2001, respectively, both for Technology Transfer; and in 2002, the Research Distinction of the Generalitat de Catalunya for contributions to microwave passive remote sensing. He was Chair of Cal '01. He is editor of the IEEE Geoscience and Remote Sensing Newsletter and President-Founder of the IEEE Geoscience and Remote Sensing Society Spain Chapter.

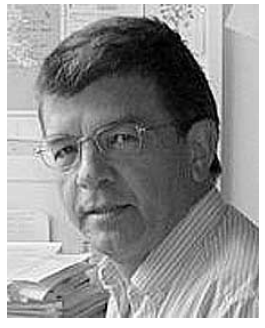

Jordi Font received the Licenciado and Ph.D. degrees in physics from the Universitat de Barcelona, Barcelona, Spain, in 1973 and 1986, respectively.

He is currently a Senior Researcher at the Institut de Ciéncies del Mar (CSIC), Barcelona, Spain, since 1991, and is responsible for the Physical Oceanography Group since 1987. He is the author and coauthor of 170 communications to scientific symposia and 70 published papers. He is Adviser of seven Ph.D. theses. He is a Principal Investigator for several Spanish and European research contracts. His main research activities are physical oceanography; the study of the marine circulation in the western Mediterranean from hydrographic, current-meter (vessel mounted, moored, and drifting), and satellite measurements; variability and dynamics of the ocean surface layer, and shelf-slope exchange processes; and the use of remote sensing of the oceans in studying the marine circulation and dynamics. He is currently Co-Lead Investigator and responsible for ocean salinity in the European Space Agency SMOS mission.

Dr. Font is a member of several international societies and committees and has participated in 41 oceanographic campaigns.

Mercè Vall-llossera (M'99) received the Senior Telecommunication Engineer and the Doctor Telecommunication Engineering degrees in 1990 and 1994, respectively, both from the Polytechnic University of Catalonia (UPC), Barcelona Spain.

She has been lecturing and doing research at the Department of Signal Theory and Communications, UPC from 1990 until 1997 as an Assistant Professor and from 1997 until present as an Associate Professor. She spent a sabbatical year in Montreal with the scholarship of the "Programme Québécois de Bourses d'excellence" (1996-1997): "Stages de Formation postdoctorale au Québec pour jeunes diplômés étrangers." Her research interests include numerical methods in electromagnetism, microwave radiometry, antenna analysis, and design. Currently, her research is mainly related to the study of numerical methods applied to the sea surface emissivity and their characterization at L-band and the MIRAS/SMOS project.

Dr. Vall-llossera, along with the other member of the radiometry group at UPC, was awarded the "Primer Premio Duran Farell de Investigación Tecnológica" in 2002, and the "Primer Premio Ciutat de Barcelona d'Investigació Tecnològica" in 2001.

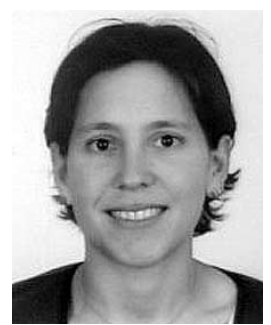

Carolina Gabarró received the degree of telecommunications engineering from the Polytechnical University of Catalonia (UPC), Barcelona, Spain, in 1998. She is currently pursuing the Ph.D. degree in microwave remote sensing at the Institute of Marine Sciences (Institut de Ciéncies del Mar, ICM), Barcelona, Spain.

In 1999-2000, she joined the European Space Agency, ESTEC, Noordwijk, The Netherlands, working in ocean color remote sensing.

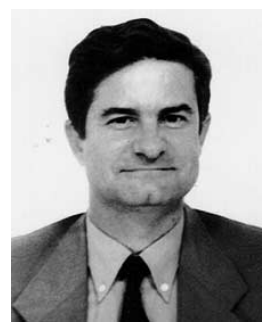

Ignasi Corbella (M'99) received the Telecommunications Engineering and Doctor Engineering degrees, both from Universitat Politècnica de Catalunya (UPC), Barcelona, Spain, in 1977 and 1983, respectively.

In 1976, he joined the School of Telecommunication Engineering in UPC as a Research Assistan in the Microwave Laboratory, were he worked on passive microwave integrated circuit design and characterization. During 1979, he worked at Thomson-CSF, Paris, France, on microwave oscillators design. In 1982, he became an Assistant Professor at UPC, an Associate Professor in 1986, and a Full Professor in 1993. He is currently teaching microwaves at the undergraduate level in UPC and has designed and taught graduate courses on nonlinear microwave circuits. During the school year 1998-1999, he worked at NOAA/Environmental Technology Laboratory, Boulder, CO, as a Guest Researcher, developing methods for radiometer calibration and data analysis. His research work in the Department of Signal Theory and Communications, UPC includes microwave airborne and satellite radiometry and microwave system design.

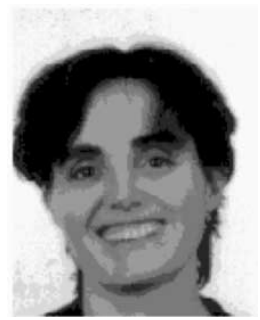

Núria Duffo (S'91-M'99) received the Telecommunication Engineer degree from the Polytechnic University of Catalonia (UPC), Barcelona, Spain, and the Doctor in Telecommunication Engineering from UPC, in 1990 and 1996, respectively.

Since 1997, she has been an Associate Professor at UPC. Her current research interests are numerical methods in electromagnetics, microwave radiometry, antenna analysis, and design.

Francesc Torres received the Ingeniero and Doctor Ingeniero degrees in telecommunication engineering from the Polytechnic University of Catalonia (UPC), Barcelona, Spain, in 1988 and 1992, respectively

In 1988-1989, he was a Research Assistant in the RF System Division, European Space Agency, Noordwijk, The Netherlands, devoted to microwave device testing and characterization. In 1989, he joined the Antenna-Microwave-Radar group, UPC, where he is currently an Associate Professor. His main research interests are focused on the design and testing of microwave systems and subsystems. He is currently engaged in research on interferometric radiometers devoted to earth observation.

Sebastián Blanch was born in Barcelona, Spain, in 1961. He received the Ingeniero and Doctor Ingeniero degrees in telecommunication engineering from the Polytechnic University of Catalonia (UPC), Barcelona, Spain, in 1989 and 1996 , respectively.

In 1989, he joined the Electromagnetic and Photonics Engineering Group , Signal Theory and Communications Department, UPC. He is currently an Associate Professor at UPC. His research interests are antenna near-field measurements, antenna diagnostics, and antenna design.

Albert Aguasca, photograph and biography not available at the time of publication. 
Ramón Villarino received the degree of telecommunications engineer from the Polytechnic University of Catalonia (UPC), Barcelona Spain, in 2000. He is currently pursuing the Ph.D. degree.

He has participated in the development and construction of an L-band radiometer in the two WISE (Wind and Salinity Experiment) field experiments sponsored by ESA from 2000 until 2002, and the FROG 2003 field experiment to determine the emissivity of foam at L-band.

Luis Enrique, photograph and biography not available at the time of publication.

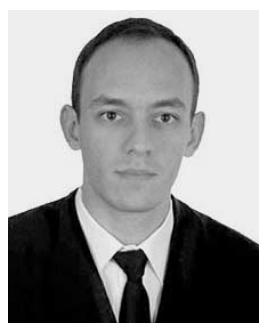

Jorge José Miranda was born in Las Palmas de Gran Canaria, Canary Islands, Spain, in 1973. $\mathrm{He}$ received the Telecommunication Technical Engineering degree from Las Palmas de Gran Canaria University (ULPGC), Spain, and the Senior Telecommunication Engineering degree from the Polytechnic University of Catalonia (UPC), Barcelona, Spain, in 1996 and 2001, respectively. He is currently pursuing the $\mathrm{Ph} . \mathrm{D}$. degree in telecommunication engineering from UPC. His Ph.D. thesis is focused on the sea surface emissivity at L-band. It includes the development of new models for determining the sea surface roughness and the comparison and improvement of existing emissivity models.

From 1996 to 1999, he was with the Remote Sensing and Radar Laboratory (EUITT-ULPGC), where collaborated in satellite image processing. In 1999, he joined the Signal Theory and Communications Department, UPC. Since 2002, he has been an Assistant Professor at the UPC.

Juan José Arenas, photograph and biography not available at the time of publication.

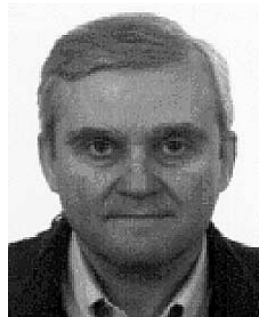

Agustí Julià studied physics and received the Ind.Eng. degree in 1973.

$\mathrm{He}$ is currently an electronics engineer. Since 1962, he is devoted to physical, biological, and chemical oceanographic instrumentation development and maintenance. He has participated in numerous sea field experiments performing hydrographic, current-meter (vessel mounted, moored, and drifting) and satellite measurements. $\mathrm{He}$ is also interested in radio and satellite telemetry.

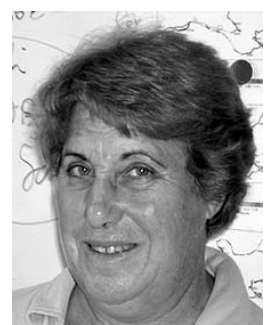

Jacqueline Etcheto was born in Meknes, Morocco, in 1943. She received the Agregation de Physique degree and the Docteur es Sciences Physiques degree for her thesis in space plasma physics in 1965 and 1972, respectively, both from the Ecole Normale Superieure de Jeunes Filles, Paris, France.

She became a Full-Time Scientist in Centre National de la Recherche Scientifique in 1965. She is presently appointed to Laboratoire d'Oceanographie Dynamique et de Climatologie, Paris, France, as Directeur de Recherches. From 1965 to 1987, she has been working on space plasma physics, focusing on studies of propagation and generation of waves in the magnetosphere. She was responsible for relaxation sounders onboard GEOS1 (ESA, 1977), GEOS2 (ESA, 1978), and ISEE1 (ESA/NASA, 1977), including instrument definition, provision of hardware, data handling, and scientific use of data. In 1988, she became interested in oceanography, using the synergy between remotely sensed measurements and in situ data to study the air-sea $\mathrm{CO} 2$ exchange at large scale. Her research activity is multiyear estimation of air-sea $\mathrm{CO} 2$ flux at regional scale using both satellite (wind speed, SST, ocean color) and in situ (PCO2 and related parameters, including launching CARIOCA buoys) data. Since 1999, she is involved in the preparation of the SMOS satellite (ESA, 2007) intended at determining sea surface salinity using L-band radiometry. She is interested in the development and validation of sea surface emissivity models at L-band, including validation campaigns. She is coordinating the group of French scientists involved in the ocean part of the SMOS project. She has published 77 papers in the open literature.

Vicente Caselles received the B.Sc., M.Sc., and Ph.D. degrees in physics from the University of Valencia, Valencia, Spain, in 1979, 1980, and 1983, respectively.

He is currently Professor of physics of the earth and Head of the Thermal Remote Sensing Group, University of Valencia, Valencia, Spain. He has an 25 years expertise in the physical processes involved in the temperature measurement using remote sensing techniques, which has been documented through 20 books, 15 doctoral theses, 150 papers in international journals, 60 conference papers, and 30 reports. He has collaborated with the European Space Agency as member of the Advisory Group for the Land-Surface Processes and Interactions Mission. He is the Manager of the Spanish Atmosphere and Climate Programme.

Dr. Caselles is the Chairman of the Spanish Remote Sensing Society.

Alain Weill received the Ph.D. degree in atmospheric sciences from the University of Paris VI, Paris, France, in 1971.

He has been with the Laboratoire de Meteorologie Dynamique du CNRS until 1975, CNET until 1991, and then at CETP/IPSL/CNRS Vélizy as a Senior Scientist. His research activity is devoted to continental and marine atmospheric boundary layer. His current research field involves particularly micrometeorological processes and related remote sensing instruments development and analysis. In complement to his research activity, he was Deputy Head of Environment programme at CNRS and now president of PRIMEQUAL, the French program on air quality at the Ministry of the Environment (MEDD). He is author and coauthor of more than 70 papers in refereed international journals.

Dr. Weill is a member of ASA and was nominated as "outstanding member" of ISARS (International Society for Acoustic Remote Sensing) in 1998.

Jacqueline Boutin received the Ph.D. degree in physical methods in remote sensing from the University Paris VII, Paris, France, in 1990.

She is currently a Research Scientist at Laboratoire d'Océanographie Dynamique et de Climatologie/CNRS, Paris, since 1992. She has widely studied the validity of remotely sensed wind speeds and the ocean/atmosphere exchange of $\mathrm{CO}_{2}$ at large scale using both satellite (wind speed, SST, ocean color) and in situ data. Since 1999, she has been involved in the preparation of the Soil Moisture and Ocean Salinity (SMOS) mission and has focused on the retrieval of ocean salinity from L-band measurements. She is a Principal Investigator on several satellite projects [ENVISAT(ESA); ADEOS2(NASA/NASDA); CoI on SMOS (ESA)] 
Stéphanie Contardo was born in Paimpol, France, in 1977. She received the B.Sc. degree in physics from the University of Rennes, Rennes, France, in 1999, and the M.Sc. degree in remote sensing from the University of Toulouse, Toulouse, France, in 2000

She is currently a Research Assistant at the LODYC, Paris, where she works on the SMOS project.

Raquel Niclós received the B.Sc. and M.Sc. degrees in physics from the University of Valencia, Valencia, Spain, in 2000, and 2002, respectively.

Since then, she is a Research Fellow of the Remote Sensing Unit, Thermodynamics Department, University of Valencia. Her current thesis research is focused on sa surface temperature (SST) determination within the SMOS Mission of the European Space Agency. She has taken part in all these unit last projects and field experiments to determine the surface temperature and develop precise and reliable surface temperature retrieval methodologies: as in WISE-2000 and WISE-2001 (Wind and Salinity Experiment, SMOS Mission), with a methodology to obtain a high-accuracy SST; SIFLEX-2002 (Solar Induced and Fluorescence Experiment of ESA), measuring the surface temperature over a canopy boreal forest target; and the ENVISAT-AATSR (Advanced Along Track Scanning Radiometer) Validation Campaign.

Raúl Rivas is currently pursuing the Ph.D. degree at the University of Valencia Valencia, Spain.

He is currently a Researcher at the Institute of Hydrology of Plains (Commission of Scientific Researches), Buenos Aires, Argentina. He has experience in the use of remote sensing in hydrology. He is developing his Ph.D. thesis on the estimation of the evapotranspiration with remote sensing data.

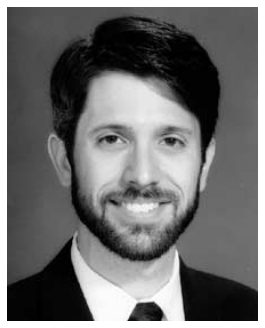

Steven C. Reising (S'93-M'98) received the B.S. and M.S. degrees in electrical engineering from Washington University, St. Louis, MO, in 1989 and 1991, respectively. He received the Ph.D. degree from Stanford University, Stanford, CA, in 1998, where his dissertation research focused on low-frequency remote sensing of lightning and its energetic coupling to the ionosphere, producing chemical changes and optical emissions.

Since 1998, he has been an Assistant Professor of electrical and computer engineering at the University of Massachusetts, Amherst. His technical interests include microwave/millimeterwave remote sensing, particularly of the ocean and atmosphere, as well as radiometer design and miniaturization using MMIC architectures. During 1999 and 2000, he was a Navy-ASEE Summer Faculty Fellow at the Naval Research Laboratory, Washington, DC, and he currently serves as a member of the WindSat Science Team. He is the current Editor and past Associate Editor of the IEEE Geoscience and Remote Sensing Society (GRS-S) Newsletter.

Dr. Reising received the URSI/USNC Best Student Paper Prize at the National Radio Science Meeting in Boulder, CO, in 1998. In 2000, he won an Office of Naval Research Young Investigator Award (YIP). He was awarded a Lilly Teaching Fellowship in 2001-2002. He is an ex-officio member of the GRS-S AdCom (without vote). He serves as Chair of the Springfield, MA, Joint Chapter of the IEEE AP, GRS, ED, MTT, and LEOS societies. He is a Member of URSI Commissions F, G, and $\mathrm{H}$, and is the Commission F Co-Chair of the International URSI Working Group on Solar Power Satellites. He is a member of the American Meteorological Society, the American Geophysical Union, Tau Beta Pi, and Eta Kappa Nu.
P. Wursteisen, photograph and biography not available at the time of publication.

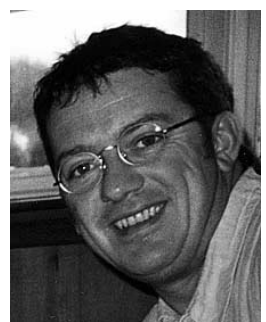

Michael Berger received the M.S. degree in geophysics and the Ph.D. degree in remote sensing from the Ludwig-Maximilians University, Munich, Germany, in 1989 and 1996, respectively.

$\mathrm{He}$ has been a Scientist with the German Aerospace Research Establishment (DLR), the Geo-Research Center Potsdam (GFZ), and has been with the National Remote Sensing Facility in Harare, Zimbabwe as a long-term expert for the German Technical Cooperation (GTZ). Since 1998, he has been a Project Scientist with the Land Unit of the Mission Experts Division, European Space Research and Technology Centre (ESTEC), European Space Agency (ESA), Noordwijk, The Netherlands. His main responsibility is the scientific definition and preparation of the Soil Moisture and Ocean Salinity (SMOS) mission, ESA's second Earth Explorer Opportunity mission, scheduled for launch early 2007.

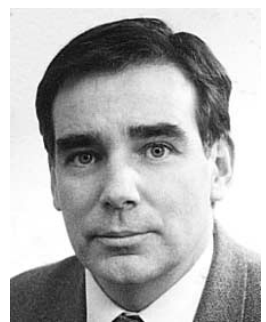

Manuel Martín-Neira (M'96) received the M.S. and $\mathrm{Ph} . \mathrm{D}$. degrees in telecommunication engineering in 1986 and 1996, respectively, from the School of Telecommunication Engineering, Polytechnical University of Catalonia, Catalonia, Spain.

From 1989 to 1992, he was was with GMV, a Spanish firm, where he was responsible for several projects for the European Space Agency (ESA) related to global positioning satellite navigation with applications to precise landing and attitude determination. Since 1992, with ESA, he has been in charge of the radiometer activities within the Payload, Equipment, and Technology Section. During this period, he has been responsible for the technology activities related to the Microwave Imaging Radiometer with Aperture Synthesis (MIRAS) project.

Dr. Martín-Neira was awarded a Fellowship to work on radiometry at European Space Research and Technology Center (ESTEC), Noordwijk, The Netherlands, in 1988. 